
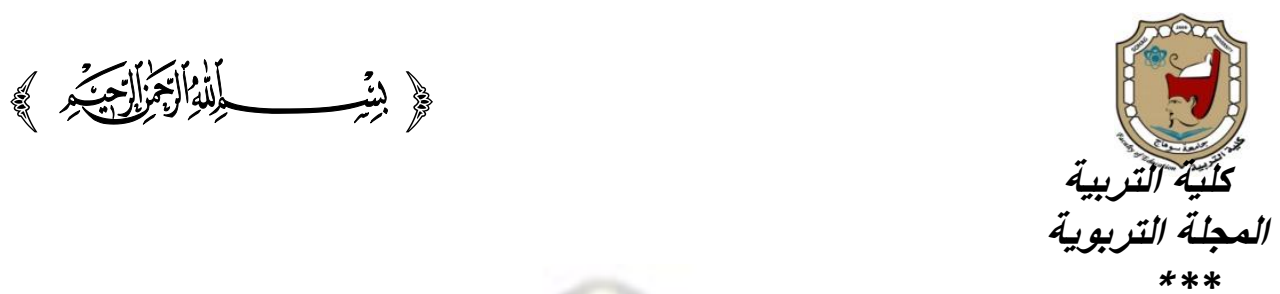

إسهام المدربة في تحقيق المواطنة الرقمية لدى طلابها في ظل التصديات المعاصرة

\title{
إعداد
}

د معجب بن أحمد معجب الزهراذي

مشرف تريوي بوزارة التعليم -تعليم جدة

$$
\text { المملكة العربية السعودية }
$$

المجالة التربوية. المدد الثامن والستوذ ـ ديسمبر 19 امبم

Print:(ISSN 1687-2649) Online:(ISSN 2536-9091) 


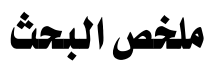

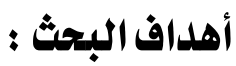

1. التأصيل النظري لمفهوم المواطنة الرقمية ، ومجالاتها ، ودواعي تحقيقها لاى الطلاب . r. التعرف على دور المدرسة في تحقيق المواطنة الرقمية لاى طلابها.

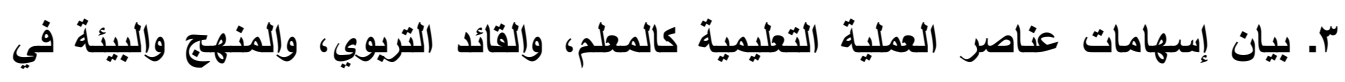

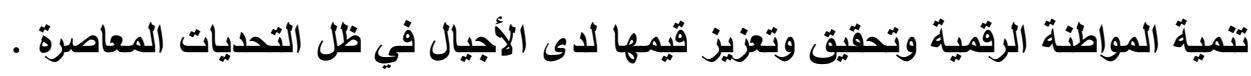

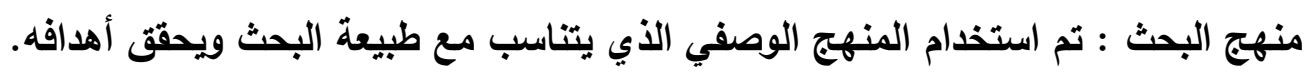

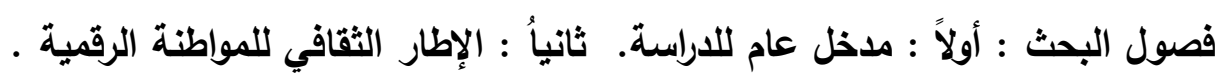

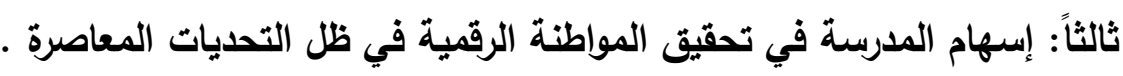
النتائج : 1. للمعلم دور في غرس قيم المواطنة الرقمية وتنميتها بتوظيف التقنية وتفعيل استراتيجيات التطلم النشط القائم على التفكير الناقد والابتكاري.

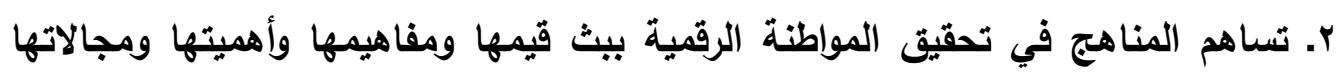

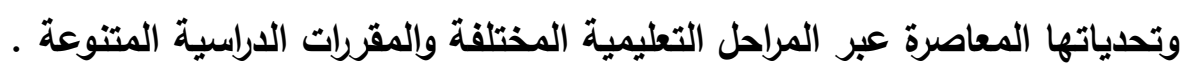

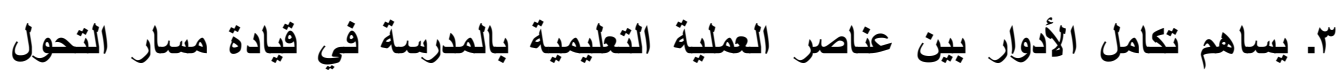
الرقمي وتثكيل شخصيه المواطن الرقمي الواعي بالاستخام الرشيد للتقنيات الرقمية . التوصيات والمقترحات: ا. وضع السياسات التي تتطلق بالمواطنة الرقمية في العدارس وآليات تنفيذها، وأدوار ومسئوليات عناصر العملية التعليمية في عمليات التنفيذ . ؛ . إجراء دراسة ميدانية عن واقع إسهام المراحل التعليمية الدراسية في تحقيق المئية المواطنة الرقمية لدى طلابنا ه. إجراء دراسة عن دور الجامعات في المملكة العربية السعودية في تحقيق المواطنة الرقمية. 
إسهام المدرسة في تحقيق المواطنة الرقمية لدى طلابها في ظل التحديات المعاصرة.

Research Summary

Research Title: School's Contribution to the Fulfilment of its Students' Digital Citizenship in the light of the Contemporary Challenges

Prepared by:

Dr . Mojeb bin Ahmed Mojeb AL-Zahrani

Research Goals/Objectives: The main objectives of this research are:

1. To lay down a theoretical framework regarding the concept of digital citizenship, its spheres of applicability, and the reasons for its attainment among students,

2. To investigate the role of the school in the fulfilment of the digital citizenship among its students,

3. To demonstrate the contributions of the educational agents and practitioners such as the teacher, the educational leader, the curriculum, and the educational environment to the development of the digital citizenship and to the fulfilment and establishment of its values among generations within the contemporary challenges.

Research Methodology

A descriptive methodology is adopted which is in congruence with the nature of this research and is deemed instrumental to achieving its objectives.

The Structure of the Research

First, a general introduction to the study is presented. The second part offers a cultural framework of the digital citizenship while third part addresses the contribution of the school to the fulfilment of digital citizenship in the light of the contemporary challenges.

Findings

1. The teacher has a great role in inculcating and enhancing the values of the digital citizenship through utilizing technology and initiating learning strategies and activities that are based on critical and innovative thinking.

2. The educational curricula contribute to the fulfilment of the digital citizenship through promoting its values, concepts, importance, spheres of applicability and its contemporary challenges throughout the different learning stages and the various teaching courses.

3. The complementary roles of the elements of the educational process at school play a major part in steering the digital transformation and in shaping the character of the digital citizen that is aware of the rational use of digital technologies.

Recommendations and Suggestions

1.The policies related to the digital citizenship in the schools have to be laid down and the mechanisms of their implementation have to be 
إسهام المدرسة في تحقيق المواطنة الرقمية لدى طلابها في ظل التحديات المعاصرة.

established.Likewise,the roles and the responsibilities of the elements of the educational process in the course of implementing those policies have to be assigned.

2. A field study regarding the reality of the contribution of the educational stages to the establishment the digital citizenship has to be conducted.

3. A study of the role of the universities in the Kingdom of Saudi Arabia in the fulfilment of the digital citizenship has to be conducted. 
أولاً : ملدخل إلى الدراسة

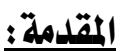

شهة العالم المعاصر تطورًا سريعاً في تقتية المطومات والاتصالات أدت لتطور الإنترنت وظهور وسائل الإعلام الجديد وشبكات التواصل الاجتماعي المتنوعة، والتي سهلت

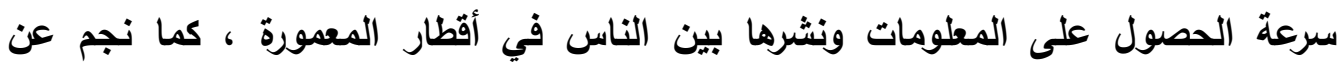
استخداماتها تثكيل الفضاء الرمزي والجماعات الافتراضية التي شكلت إطارًا جديدا لعلاقاتٍ اجتماعيةٍ وتفاعل إنساني تخطى حاجز الزمان والمكان مما أحدث تأثيراً لا يمكن إغفاله.

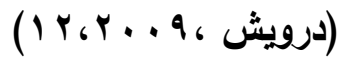

الأمر الذي فرض تغيرات في الطرق والوسائل التي يعبر بها الناس عن أفكارهم ووجهات

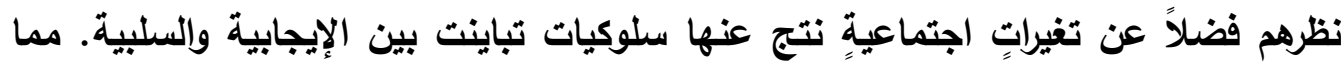

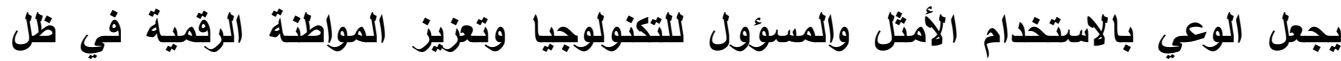

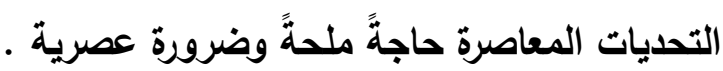
ولذا فقد زادت وتيرة الاهتمام بالمواطنة الرقمية ومفهومها في القرن الحادي والعادية والعشرين على المستويين المحلي والعالمي، وأقيمت من أجلها العليد من المؤتمرات والندوات لكونها

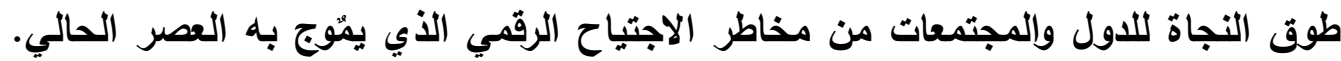

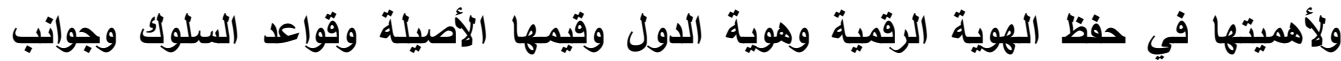

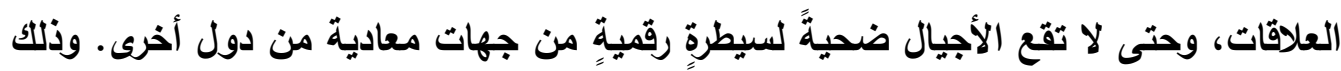
في ظل تدني ثقافة الاستخدام الرشيد لها وقلة الوعي بمهارات التهات التواصل والتعامل الأخلاقي لتلك الثبكات وإدراك حجم المخاطر والتحديات من وراء التفاصيل والصورة والصوت وما قل

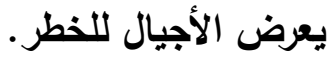
خصوصاً عندما تغيب عن الأجيال حقيقة أن المواطنة في جوهرها التزام عقائدي وأخلاقي وحضاري وسلوك يقُوم ويشارك به الفرد لصالح تنمية وطنه ومجتمعه والمؤسسة التي يُّلمل

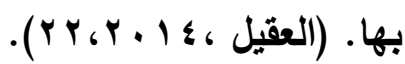
الأمر الذي يحتم عناية المؤسسات التربوية والتعليمية المساهمة بمختلف مستوياتها على بلى تحقيق المواطنة الرقمية ،وتوعية وتدريب الأجيال حول قواعد التعامل السوي مع التكنولوجيا 


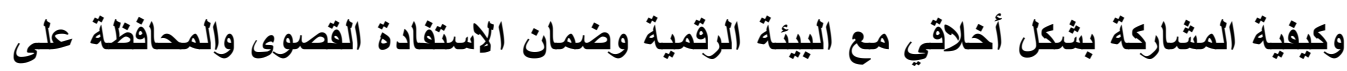
الجانب القيمي والسلوكي لهم في تعاملاتهم الرقمية. (Young Donna, 2014).

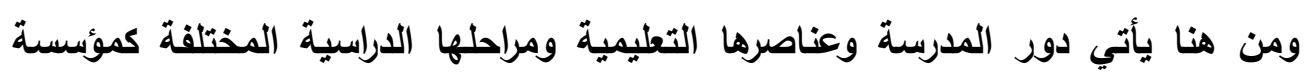

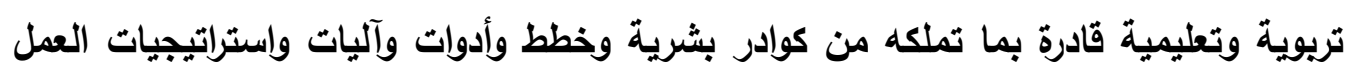

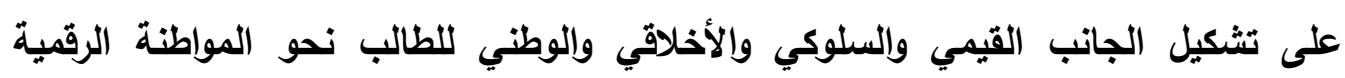

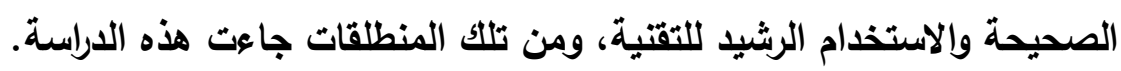

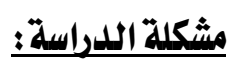
في ظل ما يمر به العالم المعاصر من تخبط قيمي وتدني للمعايير الايجابية في السلوك،

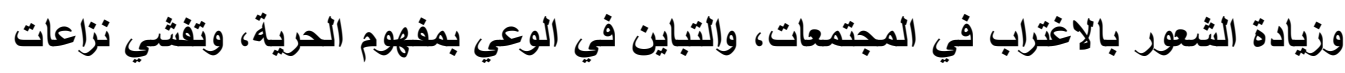

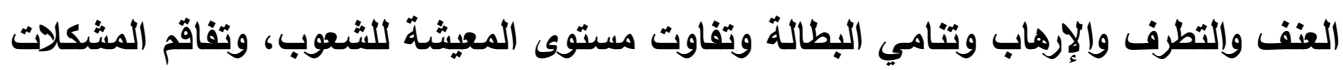

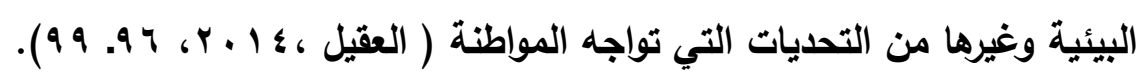

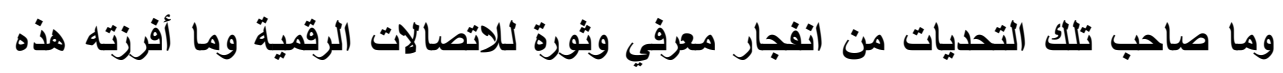

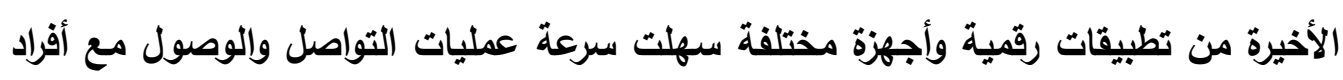

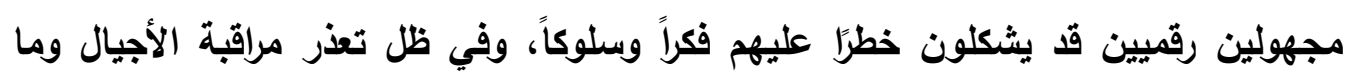
يطلعون عليه فيها من مواقع مثبوهة خطيرة أو يتبنون أفكارا وسلوكيات تخالف تعاليم وفئ الداين وقيمه وأخلاقه وتتعارض مع الثوابت الوطنية.

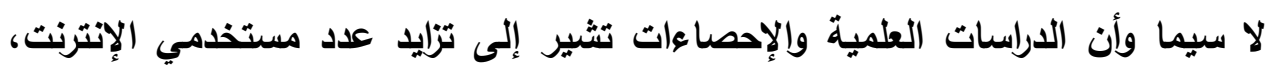
والذي تجاوز ثلاثة مليار مستخدم. وتزليد عدد مستخدمي الإنترنت في المثلكة العربية الإنية

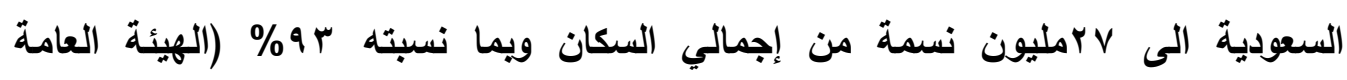

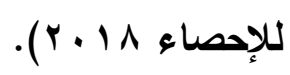

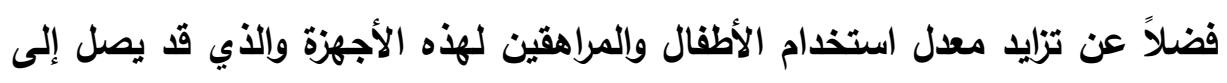

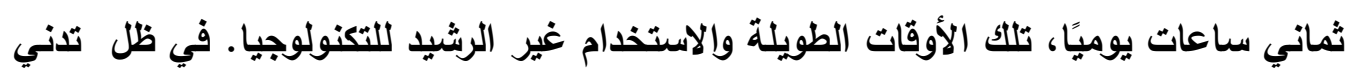

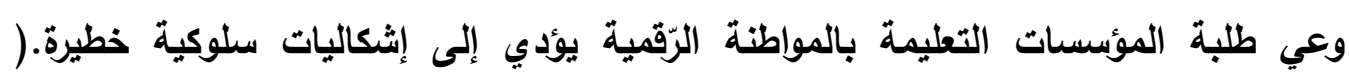

( Hollandsworth and et. al., 2011: 4

تلك التطورات التقنية المتسارعة وإفرازاتها المتعددة تؤئر على شخصية الأجيال

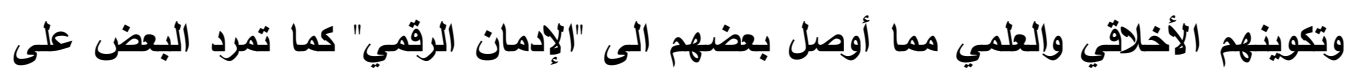




\section{إسهام المدرسة في تحقيق المواطنة الرقمية لدى طلابها في ظل التحديات المعاصرة.}

القواعد الأخلاقية والضوابط القانونية والمبادئ الأساسية التي تنظم شؤون العياة الإنسانية. حتى أضحت تتحدى المربين القائمين على التربية والتعليم.

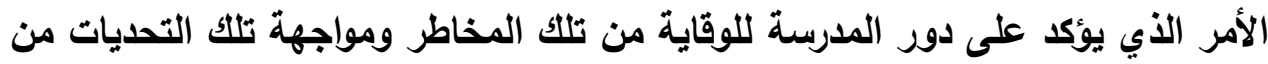
خلال تعزيز ونشر ثثافة المواطنة الرقمية في مدارسنا وبين صفوف طلابنا من برامجاج

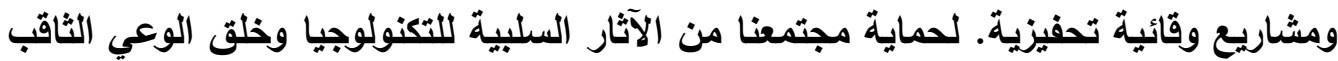

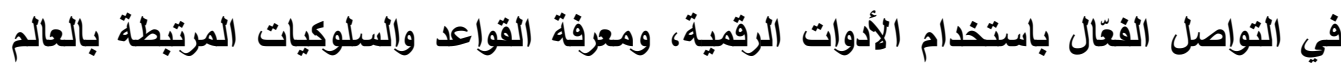
الرقمي، والعواقب التي قد يواجهونها إذا تم انتهاك تلك القواعد. وفي ضوء ما سبق يمكن تحديد مشكلة الدراسة في محاولة الإجابة عن السؤال الرئيس

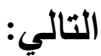

ما إسهام المدرسة في تحقيق المواطنة الرقمية لاى طلابها في ظل التحديات المعاصرة ؟ ويتفرع من هذا السؤال التساؤلات الفرعية الآتية: 1- ماهي المواطنة الرقيمة ؟ وما دواعي تحقيقها لدى الأجيال ؟ r - كيف يساهم المعلم في تحقيق المواطنة الرقمية لاى الطلاب ؟

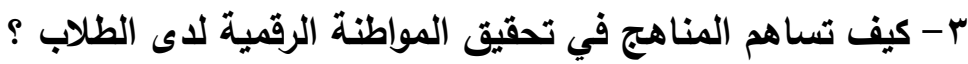
ع - كيف يسهم القائد التريوي في تحقيق المواطنة الرقمية لدى الطلاب ؟ ه - كيف تسهم البيئة المدرسية في تحقيق المواطنة الرقمية لاى الطلاب ؟

أهدافاللدراسة:

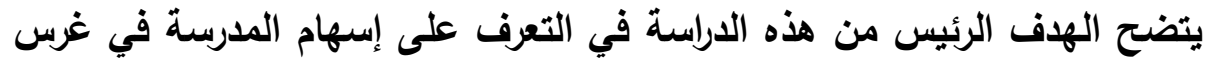
وتنمية قيم المواطنة الرقمية في نفوس طلابها في ضوء التحديات المعاصرة، وذلك من خلال تحقيق الأهداف الفرعية الآتية :

1. التأصيل النظري لمفهوم المواطنة الرقمية ، ومجالاتها ، ودواعي تحقيقها لاى الأجيال . r. التعرف على دور المدرسة في تحقيق المواطنة الرقمية لاى طلابها. r. بيان إسهامات عناصر العملية التعليمية كالمعلم، والقائد التريوي، والمنهج والبيئة في تنمية المواطنة الرقمية وتحقيق وتعزيز قيمها لاى الأجيال في ظل التحديات المعاصرة . 


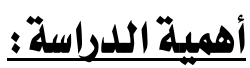

تتبين أهمية هذه الدارسة فيما يلي:

- - تيتاول الدارسة المواطنة الرقمية التي هي أحد أهم التحديات المعاصرة التي تواجه

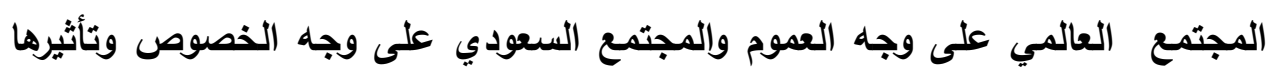
على مستقبل الأجيال.

- تأتي الدراسة استجابة للتوجهات التريوية المعاصرة، كما أنها متزامنة مع الجهود

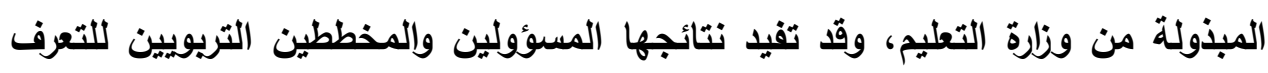
على واقع إسهام المدرسة في تحقيق المواطنة الرقمية ووضع الخطط التهات اللازمة للإرتقاء

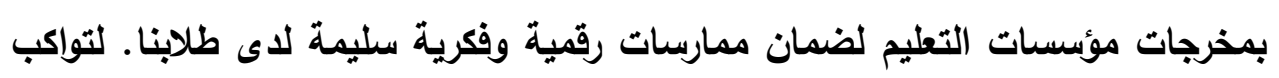

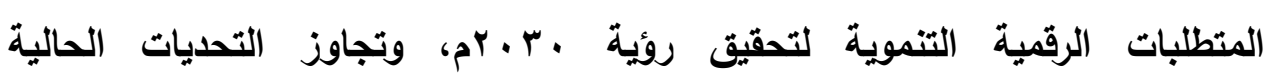
والمستقبلية. - تُّنى الاراسة بتحديد دور المدرسة ومسؤولياتها في دعم وتعزيز قيم المواطنة الرقمية،

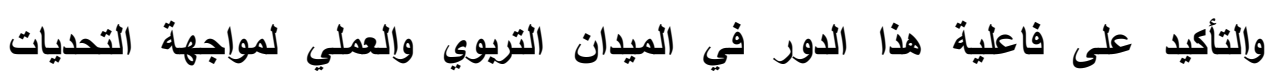

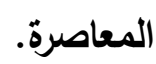

- تسعى الدراسة الى بيان اسهام المعلم والثقائد التريوي والمنهج والبيئة المدرسية في تنمية المواطنة الرقمية وتحقيق المواطنة الصالحة.

حلدود اللدراسة:

الحدود الموضوعية : إسهام المدرسة في تحقيق المواطنة الرقمية لاى طلابها في ظل

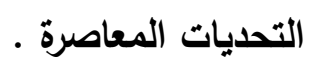

الحدود المكانية :_مدارس وطلاب المرطلة المتوسطة والثانوية بالمملكة العربية السعودية.

\section{مصطلحات اللدراسة:}

عُرَّتَ المواطنة الرقمية بأنها : قواعد التواصل المسؤول والمناسب مع التكنولوجيا ليتمكن الأفراد من الحياة بأمان في العصر الرقمي( Bolkan, 2014: 21 ).

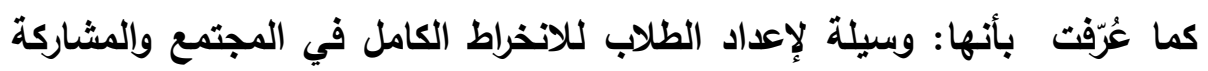
الفاعلة في خدمة مصالح الوطن عمومًا وفي المجال الرقمي خصوصًا. (القايد، 2014 ) . 


\section{إسهام المدرسة في تحقيق المواطنة الرقمية لدى طلابها في ظل التحديات المعاصرة.}

التعريف الإجرائي للمواطنة الرقمية: كل ما يمكن أن تسهم به المدرسة بكافة مقوماتها من جهود مخططة لتمية اتجاهات وميول وقيم ومهارات الطلاب للتعامل مع التقتية وحمايتهم من أخطارها، والالتزام بمعايير السلوك المقبول عند استخدامها لما يحقق المصلحة المجتمعية والمواطنة الصالحة ورفعة الوطن.

\section{اللدراسات السيارقة:}

وجد الباحث الكثير من الدراسات العربية والأجنبية حول مجال الدراسة ويعيدًا عن الإسهاب في استعراضها تم اختيار الأقرب لمجال الدراسة والأحلث زمانياً حيث سيتم بيانها

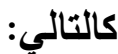

\section{أولاً :الدراسات المحلية والعرية:}

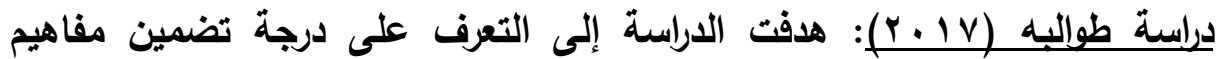
المواطنة الرقمية في كتب التربية الوطنية والمدنية بالأردن ، والمام معلمي تلك الكتب بها. واعتمد الباحث المقابلات وتحليل المحتوى في جمع بيانات الدراسة. وأثثارت نتائج الدراسة إلى خلو جميع كتب التربية الوطنية والمدنية من استخدام مصطلح المواطنة الرقمية، وأن الوصول الرقمي ومحو الأمية الرقمية هما المحوران اللأن وردت بعض مفاهيمهما في الكتب. كما أثارت النتائج إلى تدني معرفة معلمي التربية الوطنية والمدنية بشكل كبير بمحاور ومفاهيم المواطنة الرقمية.

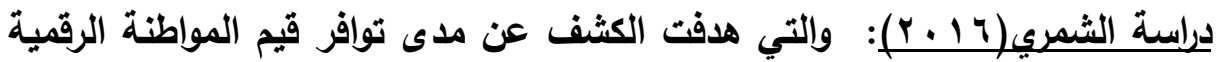
لاى معلمي الحاسب الآلي وتقتية المعلومات في المرحلة المتوسطة والثانوية بمحافظة حفر الباطن بالسعودية وسبل تعزيزها. حيث تم عقد مقابلة مع 1 ـ معلما في مدارسهم للإجابة عن الاستبانة المفتوحة، وقد أظهرت نتائج الدراسة توافر قيم المواطنة الرقمية لاى المعلمين

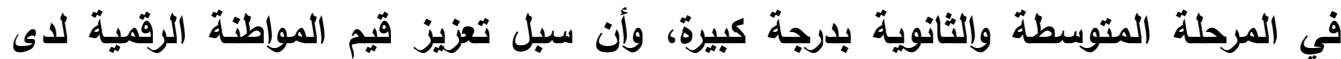
معلمي الدراسة كانت بدرجة كبيرة جداً. دراسة الحصري( (1 ب ب): وهدفت للكثف عن مستوى معرفة معلمي الدراسات

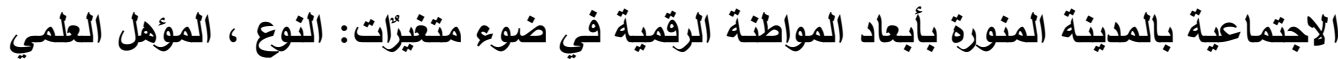
، المرحلة، الخبرة، الدورات. واستخدمت الدراسة المنهج الوصفي التحليلي وقد توصلت الدراسة إلى انخفاض درجة معرفة المعلمين بأبعاد المواطنة الرقمية، ووجود فروق ببين 


\section{إسهام المدرسة في تحقيق المواطنة الرقمية لدى طلابها في ظل التحديات المعاصرة.}

متوسطات تقديرات أفراد العينة بين متغيرات الدراسة وقد أوصت الدراسة بضرورة تدريب معلمي الاراسات الاجتماعية على أبعاد المواطنة الرقمية وإدخالها ضمن برامج الإعداد والتدريب.

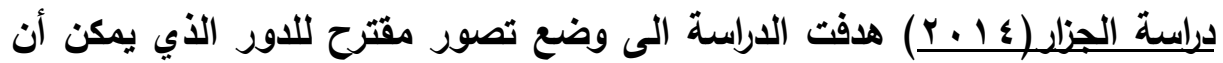
تقوم به المؤسسة التريوية في غرس قيم المواطنة الرقمية لاى الطلبة، واستخدمت الدراسة المنهج الوصفي، وتوصلت إلى أن ترسيخ قيم المواطنة الرّقمية لاى الطلاب يستلزم وضع ضوابط ومعايير لتعاملهم مع الوسائط الرقية ، وقدمت تصور مقترح يشتمل على تطوير البيئات التعليمية الاعمة للتكنولوجيا الرقمية، وضوابط ومعايير للتعامل الرقمي ومقترحات لتعظيم الدور التربوي للمدرسة في اكساب الطلبة القواعد اللازمة للمواطنة الرقمية المثلى.

\section{ثانيًا : اللدراسات الأحنبية:}

دراسة (دوتير وآخرون Dotterer and Others 2016 ): وهدفت التشجيع على ممارسة المواطنة الرّقمية في مجالات التعليمٌ المختلفة بالولايات المتحدة، وقد استخدمت الدراسة المنهج الوصفي وتوصلت إلى أن تدريس المواطنة الرّقمية يساعد على محو الأمية

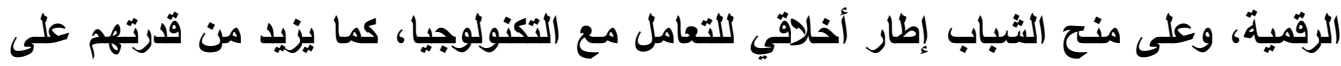

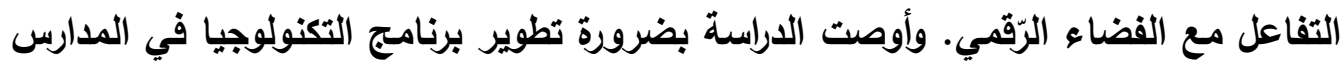
بحيث تكون المواطنة الرقمية جزءاً أساسياً فيه، وأن تتاح الفرصة لأولياء الأمور للمشاركة في تطوير المناهج الدراسية.

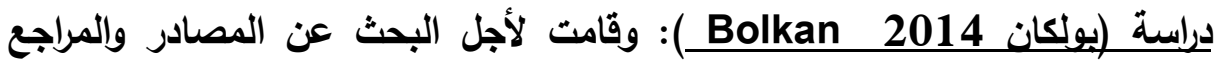
التي يمكن أن تساعد على تعليم المواطنة الرّقمية لطلبة المدارس، وقد استخدمت الدراسة المنهج الوصفي، وتوصلت الدراسة إلى قائمة بأسماء المواقع والكتب التي يمكن الاعتماد عليها في تدريس المواطنة الرّقمية للطلبة، كما توصلت إلى أن المديرين والمعلمين والطلبة

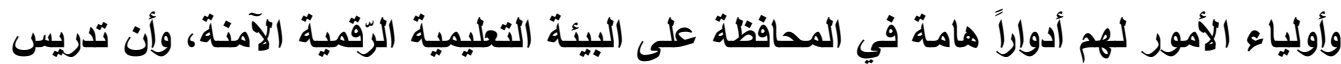
المواطنة الرقمية يعد عنصراً هاما في أي إستراتيجية تعليمية ونتائج أفضل من فرض الرقابة 
دراسة( رييل Ribble 2014 : وقد هدفت إلى بيان أهمية المواطنة الرّقية في المدارس، وأهية توظيفّ التكنولوجيا بالمدرسة، وقد استخدت الدراسة المنهج الوصفي،

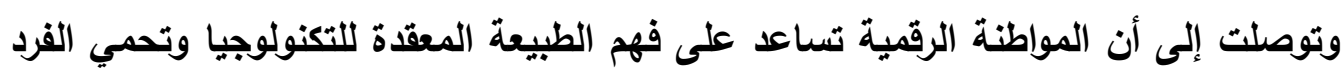

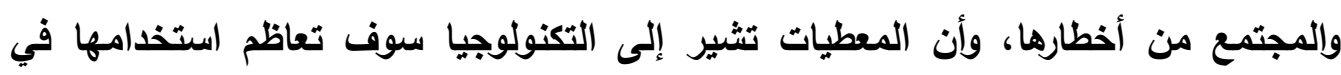

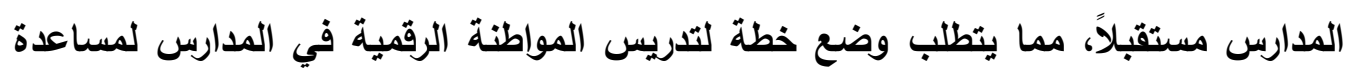
الطلبة على التعامل مع المستقبل الرقبي.

التعقبيب على اللدراسات السابقة:

في ضوء العرض السابق للاراسات السابقة، يمكن القول بأن: الدارات الساتئة السابقة

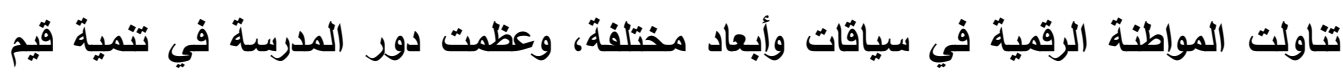

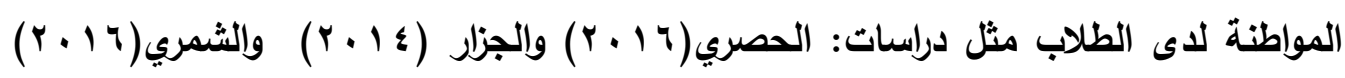

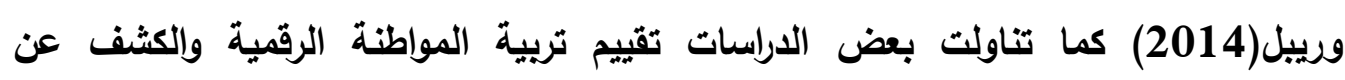

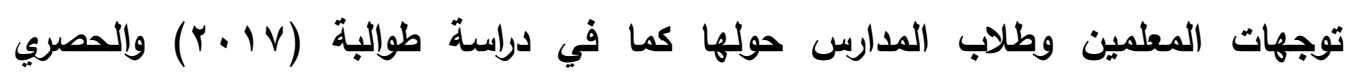

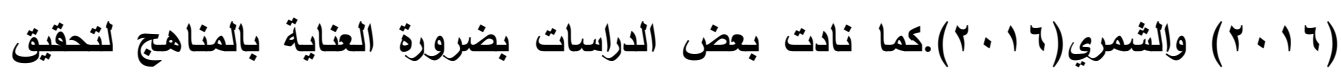

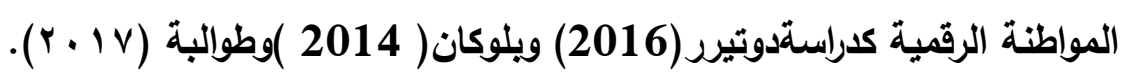

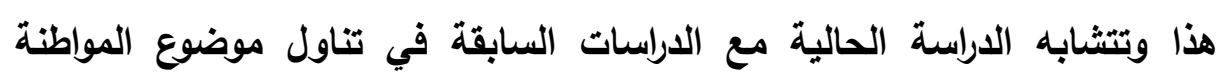

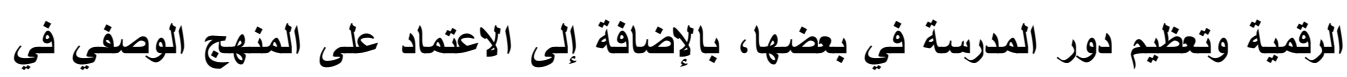

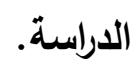

كما تختلف الدارسة الحالية عن الاراسات السابقة في أن الدراسة الحالية تسعى

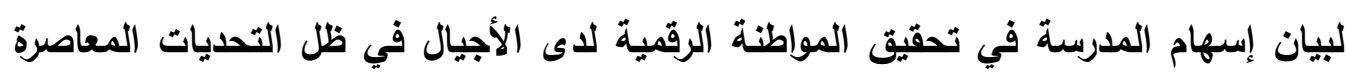

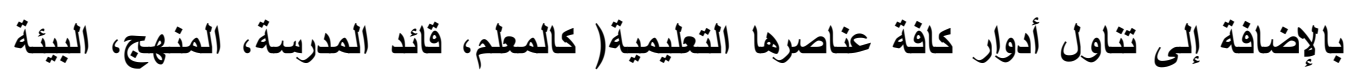

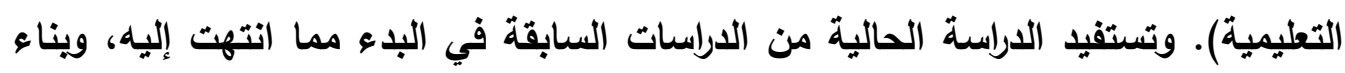
ودعم الإطار النظري . منهجج اللدراسة: تحقيقًا لأهداف الدراسة تم استخدام المنهج الوصفي الذى يتناسب مع طبيعة الدراسة وأهدافها، بعرض وتحليل الأدب التربوي والدراسات السابقة ذات الصلة، لبيان إسهام المدرسة الونة 
في تحقيق قيم المواطنة الرقية من خلال عناصر العملية التعليمية في ضوء التحديات المعاصرة.

\section{ثانياً : الإطار الثقافي للمواطنة الرقمية}

يمكنا بيان الإطار الثقافي للمواطنة الرقمية من خلال المحاور الثلاثة التالية :

\section{المحور الأول : مفهوم المواطنة الرقيبة وأهدافهيا:}

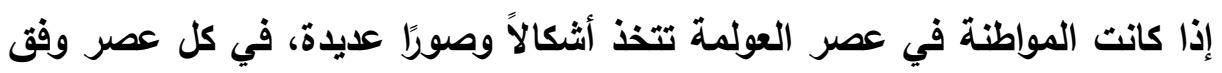
متغيراته ، فإنه في ظل طبيعة ومتغيرات العصر الرقمي وظهور وانتشار تكنولوجيا المعلومات

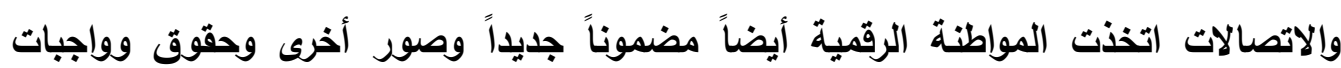

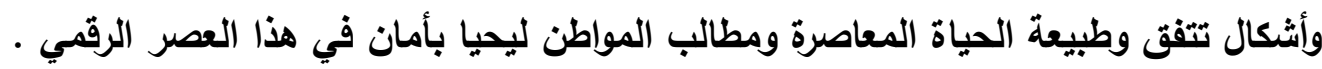

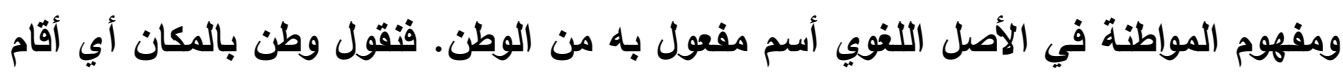

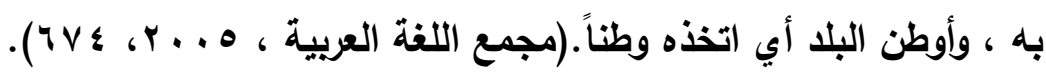

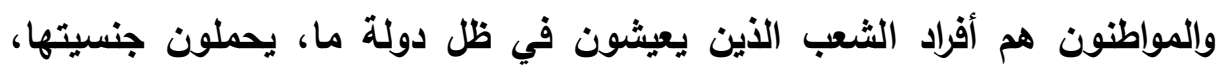
ويتمتعون بكافة الحقوق والواجبات المكفولة داخل نطاقها ( ابن منظور، ؛ 9 و 1 ، 0 ؛ ).

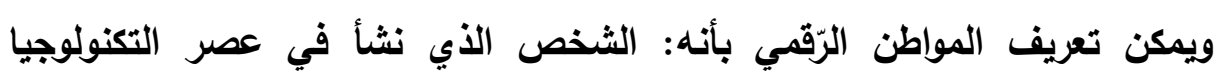

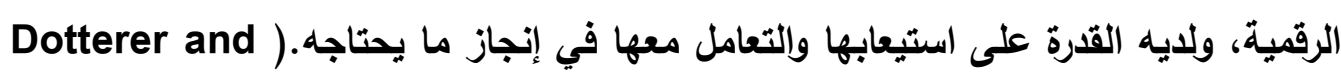
(et. al., 2016: 59

وفي الاصطلاح تزخر كثير من الأدبيات بالعديد من التعريفات للمواطنة الرقمية

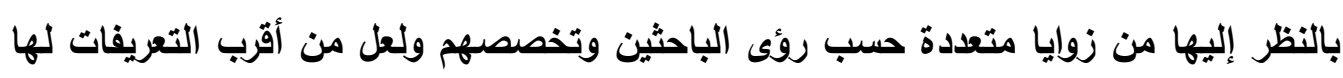

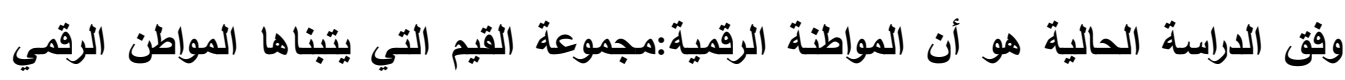

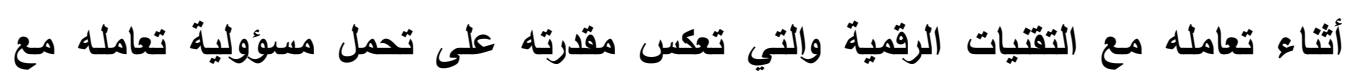

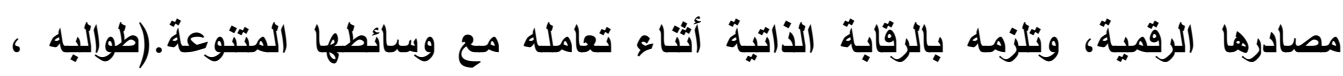

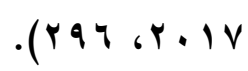
ويالتالي فإن المواطنة الرقمية تهدف إلى إيجاد الطريق الصحيح لتوجيه وحماية

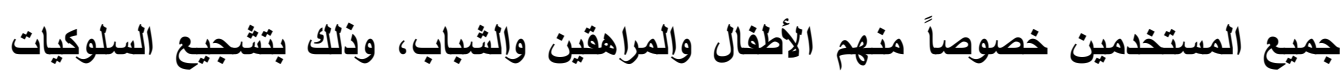

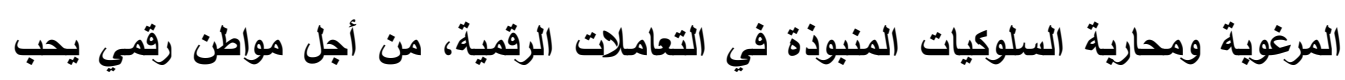

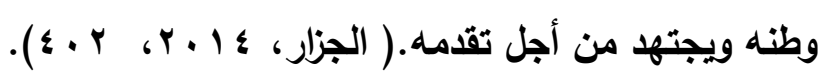




\section{إسهام المدرسة في تحقيق المواطنة الرقمية لدى طلابها في ظل التحديات المعاصرة.}

ومما سبق يمكننا القول بأن مفهوم المواطنة الرقمية يتضمن عدد من الأمور لعل

من أبرزها:

1. إدراك حقيقة العالم الرقمي ومكوناته.

r. امتلاك مهارات الممارسة الفعالة والمناسبة في استخدامات العالم الرقمي بآلياته المختلفة.

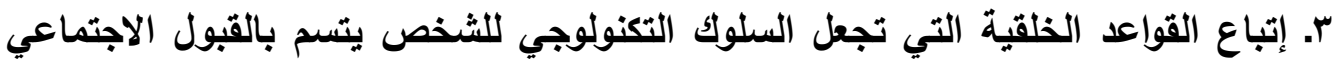
في التفاعل مع الآخرين.

ع. إنها تتضمن مجموعة من الحقوق والواجبات والالتزامات فيما يتعلق بالتقتيات الرقمية. ه. إنها هامة لإقامة المجتمع الصالح وحماية المجتمعات من الآثار السلبية المتزايدة

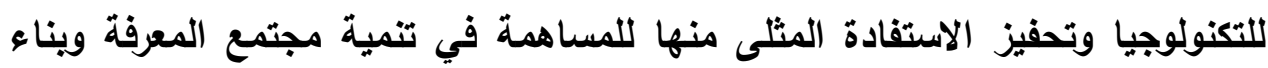
الاقتصاد الرقمي الوطني. I. إنها هامة لوقاية أجيالنا من التخريب الرقمي والحروب والجريمة الرقمية، والأضرار

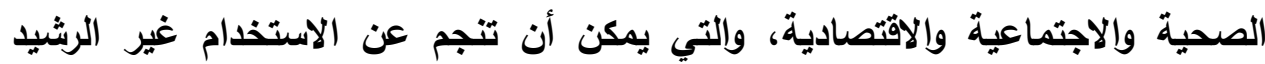

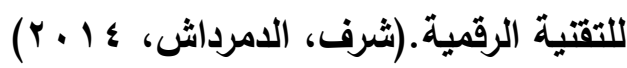

\section{الأهداف التي يجب أن نحققها من خلال الملدرسة في نشر ثقافة المواطنة الرقمية :} يتضح مما تم ذكره في الفصل التمهيدي للاراسة ومن الأمور المذكورة أعلاه أن الهلف الأساسي في التعليم تجاه المواطنة الرقمية هو : نثر الوعي الرقمي وإكسابهم مهاراته

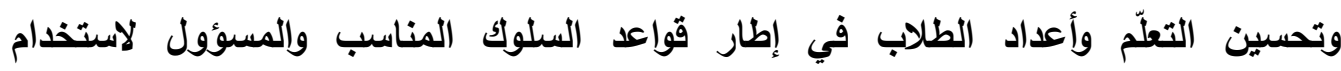

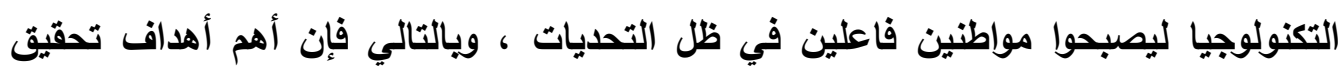
المواطنة الرقمية من خلال المدرسة هي :

ا. تمثيل المملكة العربية السعودية بأفضل صورة ممكنة من خلال السلوك الرقمي السليم. r. توعية مختلف المراحل العمرية بمفهوم المواطنة الرقمية بصورة جاذبة لرفع مستوى الأمان

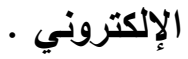

r ـ تقليل الإنعكاسات السلبية لاستخدام الأنترنت على الحياة الواقعية .

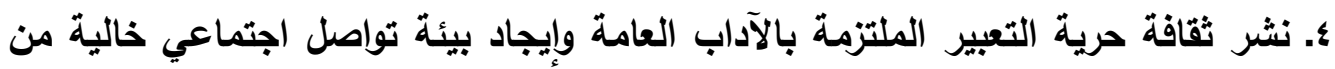




\section{إسهام المدرسة في تحقيق المواطنة الرقمية لدى طلابها في ظل التحديات المعاصرة.}

ه ـ بيان الطرق المثلى لتعامل الفرد مع موقف أو قضية إلكترونية معينة عبر إعداد مرجع متكامل للقضايا الإلكترونية المنتشرة.

צ. تحويل مفهوم الرقابة المشددة وإنعام الخصوصية إلى مفهوم الرقابة الأتية وفق ضوابط

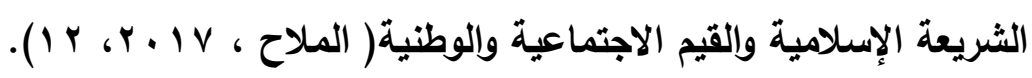

المحور الثاني: مجالات المواطنة الرقمية:

اتفق الباحثون على أن للمواطنة الرقمية، تسعة مجالات هامة لاستخدام التقتية

بشكل ملائم، وتثكل الأساس الأي يقوم عليه المجتمع الرقمي يمكن بيانها وفق التالي : ا. الوصول الرقمي: أي أن لاى كل فرد ما يؤهله من تكنولوجيا للمشاركة الكاملة في المجتمع الرقمي بشكل كامل بلون عائق ويطريقة صحيحة.

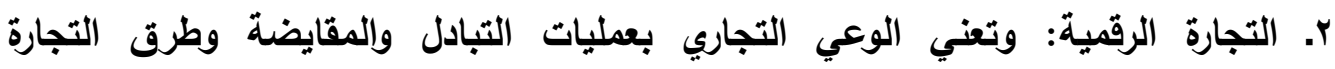
الاكترونية عبر الإنترنت ليكون مستهلكاً فعالاً في عالم جليد من الاقتصاد الرقي

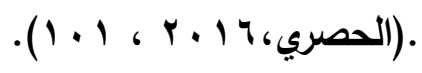

rـ الاتصال الرقمي : وهو التبادل الإكتروني للمعلومات مع الآخرين ، وفهم ما يجب تبادله وما لا يجب للبعد عن المحاسبة القانونية. عـ الثقافة الرقمية: وتعني القدرة على استخدام التكنولوجيا الرقمية بمسؤولية، ومعرفة متى يستخدمها في ظل مجتمع جديد.

ه. قواعد السلوك الرقمي والتي تمثل معايير للسلوك أو الإجراءات المتوقعة من قبل مستخدي

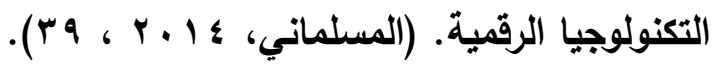

4. القانون الرقمي : ويعبر عن الحقوق والقيود القانونية، التي تحكم الاستخدام التقني بالبعد

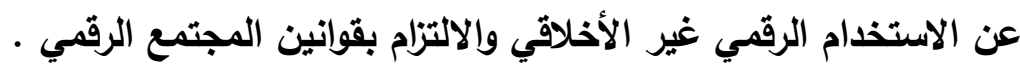

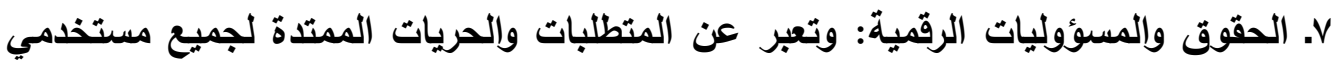
التكنولوجيا الرقمية والتوقعات السلوكية وكذلك المسؤوليات التي تتناسب مع طبيعة

$$
\text { الحياة في العصر الرقمي وعواقب ارتكابها. }
$$

^. الصحة والرفاهية الرقمية: وتتعلق بالهيئة الجسدية والنفسية لبنية الجسم المتعلقة باستخدام التكنولوجيا الرقمية. وما تتطلبه من ثقافة وأساليب لمستخدمي التكنولوجيا لحماية أنفسهم وعقولهم منها وذلك عبر التعليم والتدريب. 


\section{إسهام المدرسة في تحقيق المواطنة الرقمية لدى طلابها في ظل التحديات المعاصرة.}

9. الأمن الرقمي: ويتمثل في الاحتياطات التي يجب أن يتخذها جميع مستخدمي التكنولوجيا لضمان سلامتهم الشخصية وما لايهم من معلومات وأمن شبكتهم بعدم إمكانية الوصول لها من أي شخص آخر أو جهة معادية.(Ribble, M., 2014,88) المحورالثالث: دواعي العنساية بتحقيق المهاطنة الرقمبة للدى الطلاب: لا شك أن نشر ثقافة المواطنة الرقمية لاى الأجيال في ظل التحديات المعاصرة وخصوصاً في المدارس ويين صفوف الطلاب أصبح ضرورة ملحة، حتى نتمكن من حمايتهم

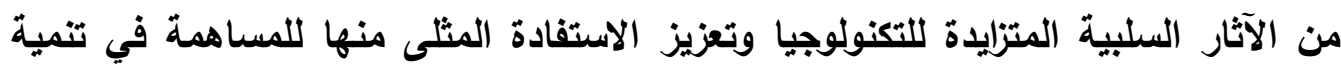
المجتمع ولعل ذلك الاهتمام يعود للاواعي التالية: 1- تزايد عدد مستخدمي الإنترنت في المملكة العربية السعودية بشكل متسارع حيث rrv

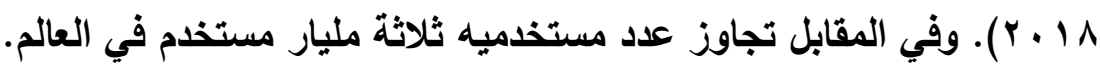
إضافة إلى الاعتماد المتزايد على التقتية في معظم جواتب حياتنا، حيث أثنارت الدراسات

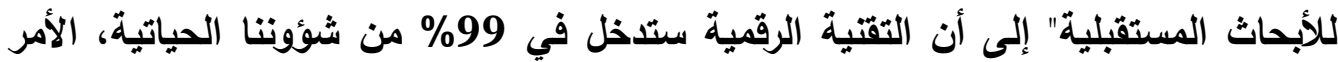
الذي سيؤدي لزيادة نسبة الجرائم الإكترونية نتيجة لقلة الوعي وعدم وجود ثقافة مجتمعية في التعامل معها؛ مما يستوجب بذل مزيد من الجهود للمساهمة في توعية المجتمع بعدد من لن

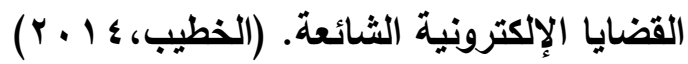
r- إن موضوع المواطنة الرقمية يكتسب زخمًا كبيرًا في جميع أنحاء العالم، حيث أصبحت تحتل جوهر التحول الحكومي والوطني في العصر الحديث . r- إن نشر ثثافة المواطنة الرقمية في المدرسة وبين صفوف الطلاب أصبح ضرورة ملحة، مما يستوجب أن تتحول إلى قيم ومبادئ ويرامج ومشاريع في مدارسنا للتكامل مع مبادرات المجتمع المدني والمؤسسات الإعلامية، حتى نتمكن من تعزيز وحماية

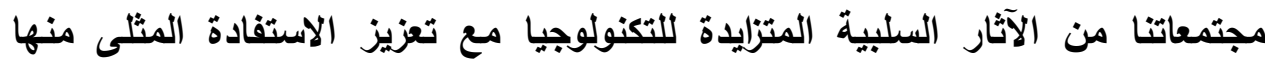
للمساهمة في تنمية مجتمع المعرفة ويناء الاقتصاد الرقمي الوطني.(عبد الحميا ،

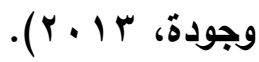

؟ - إن مفهوم المواطنة الرقمية له علاقة قوية بمنظومة التعليم، لأنها الكفيلة بمساعدة المعلمين والتريويين عموما وأولياء الأمور لفهم ما يجب على الطلاب معرفته من أجل 
استخدام التقتية بشكل مناسب. ولكونها وسـيلة لإعداد الطلاب للانخراط الكامل في المجتمع والمشاركة الفاعلة في خدمة مصالح الوطن عموما وفي المجال الرقمي

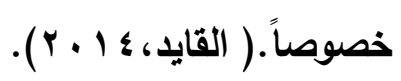

ه- إن التقتية ووسائل الاتصال الحديثة لم تعد من سبيل الترفيه والتسلية، بل أضحت

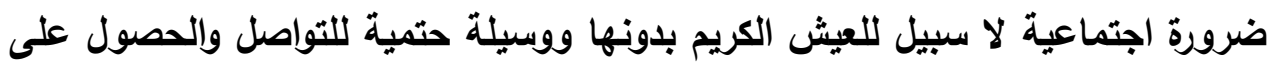
الكثير من الخدمات التعليمية والمعرفية والحياتية، مما يحتم تعريف أبنائنا بالقواعد والضوابط والتوجيهات اللازمة للتعامل الرشيد مع تلك التقنية بحيث تصبح ثقافة إيجابية وعوامل تظوير ويناء بدلاً أن تكون عوامل هدم وتدمير) \&

.Kyle, Bobbi ,2014

צ- إن روح التمرد التي خلقها الإعلام الرقمي عموما أوجدت آثثار سلبية على الروح الوطنية

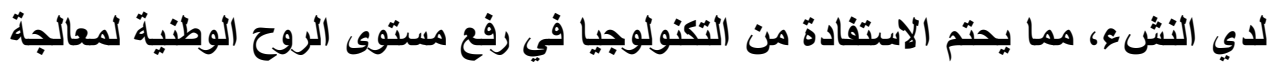

ذللك التحدي • (الدهشان والفويهي ،2015 ) V - إن حياتنا اليومية ويشكل متزايد تحولت لحياة رقمية وأصبحنا نستخدم بكثافة تكنولوجيا المعلومات والاتصالات والتقتيات الحديثة للمشاركة في الأنشطة الاجتماعية والتعليمية وإلثقافية والاقتصادية وغيرها، مما يحتم على المواطنين تعلّم وممارسة كثير من الأن الأساليب التقتية المتقدمة لمواكبة التقدم التقني المعاصر ومنها التوعية بالسلامة والأمن الإلكتروني، وتعلم ثقافة وآداب التعامل الرشيد مع تلكك التكنولوجيا الرقمية. ^- أنه على الرغم أن التكنولوجيا الرقمية دعامة أساسية لتحفيز الابتكار والإبداع والتعلم ودفع عجلة التنمية الاقتصادية، فإنها تجعل الانسان أكثر عرضة لأشكال الجرائم

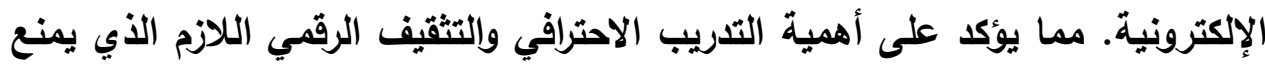
الاستغلال الإكتروني الأي يترك آثثاراً سلبية على المستويين الشخصي والمهني.) الثافعي، 2005).

ثالثاً : إسهام المدرسة في تحقيق المواطنة الرقمية في ظل التحافية التحليـات المعاصرة لعلنا قبل الحديث عن اسهام المدرسة في تحقيق المواطنة الرقمية من خلال عناصرها المتعددة أن نشير إلى أن المدرسة مؤسسة تريوية وتعليمية واجتماعية تمثل بيئة اجتماعية

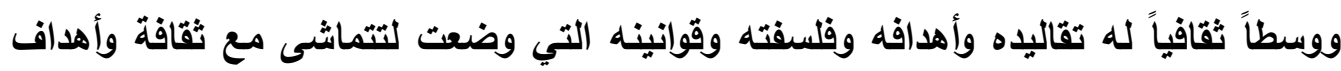


وفلسفة المجتمع التي هي جزء منه، تتفاعل فيه ومعه، بهذف تحقيق أهدافه الاينية والسياسية والاجتماعية والاقتصادية.

ولذا توجد عدة منطلقات تبرز دور المدرسة في تربية المواطنة بصفة عامة والمواطنة الرقمية بصفة خاصة لعل من أهمها:

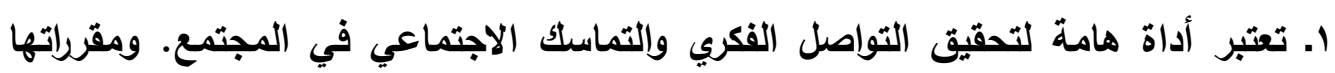

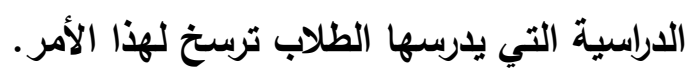

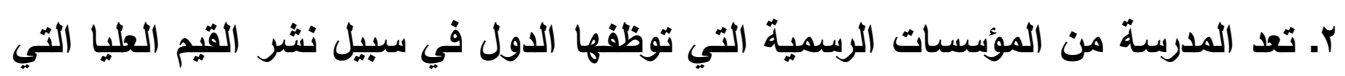

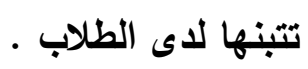
بأنها تؤثر في الفرد وتعدل من سلوكه، وتكسبه المعلومات والمهارات المختلفة التي تساعده

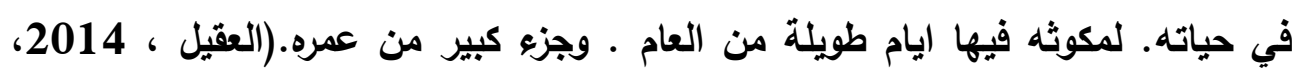
.) (AV ، A

ولهذا يمكنتا بيان إسهام عناصر العملية التعليمية بالمدرسة في تحقيق المواطنة الرقمية في ظل التحديات المعاصرة من حلال الإيضاح التالي:

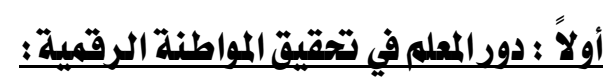
يظل المعلم حجر الززاوية ومرتكز العملية التعليمية والتريوية فهو المرثد والمدربي والمينيس

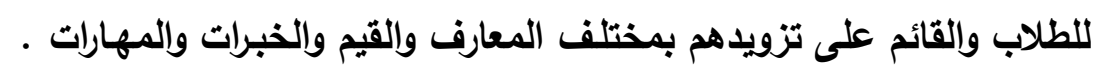

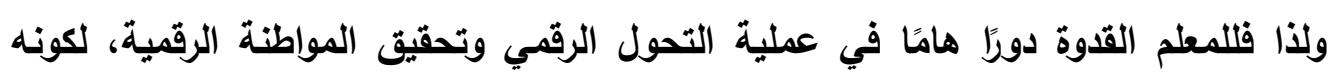

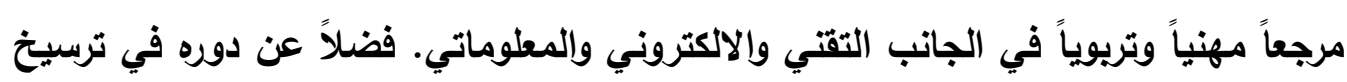

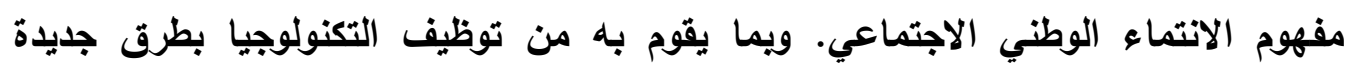

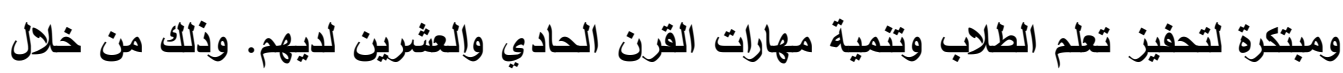

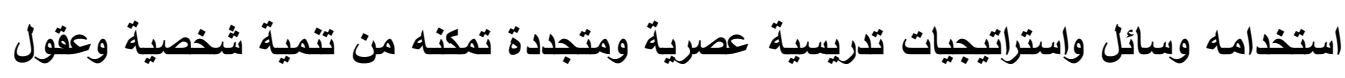

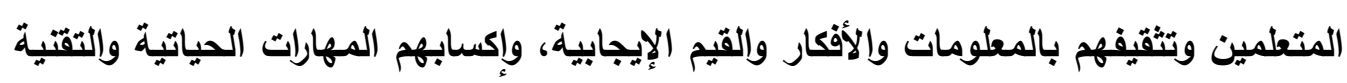

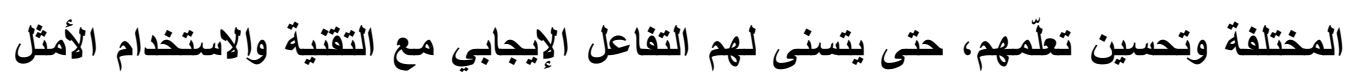

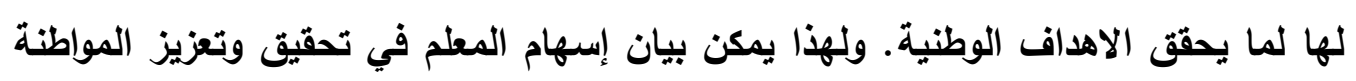

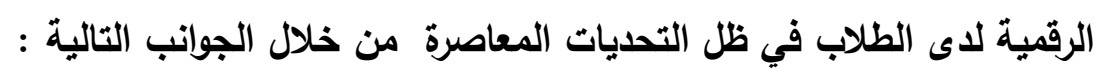




\section{إسهام المدرسة في تحقيق المواطنة الرقمية لدى طلابها في ظل التحديات المعاصرة.}

• تعريف الطلاب بجوهر المواطنة الرقمية، ومنظورها الثرعي والذي يرتكز على كونها

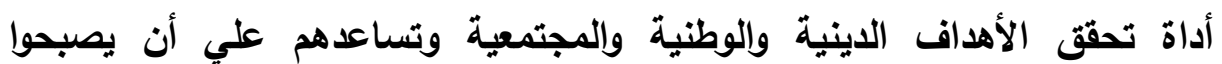
مواطنين صالحين فاعلين. • تنمية قدرة الطالب على التحول الرقمي واستخدام التكنولوجيا الرقمية، ومعرفة متى وكيف يمكن استخدامها، وتدريبهم على التحكم في سلوكياتهم عند استخدامها. • توعية وتدريب الطلاب علي كيفية الحصول على المعلومات بمختلف أنواعها بطرائق شرعية وأخلاقية وقانونية. • تمية وعي الطلاب بأهمية التفكير فيما ينشر على الإنترنت، وما له من آثار، وكيفية التحقق من مصداقية المواد المنشورة. • تدريب الطلاب على الإلمام بالمفاهيم الأساسية للاتصال الأخلاقي والقيمي، وعواقب استغلال التكنولوجيا في القيام بأعمال إجرامية أو جرائم معلوماتية. • تعريف الطلاب بعناصر الأمن والسلامة البذنية والنفسية المرتبطة باستخدام التكنولوجيا والفضاء السيبراني، وتوعيته بالمخاطر الناجمة عن الاستخدام الغير صحيح. • توعية الطلاب بمخاطر إدمان الإنترنت، وما لذلك من آثار خطيرة تتمثل في الانعزال عن المجتمع، والاكتفاء ببناء مجتمع افتراضي. • تنمية وعي الطلاب بمخاطر الانفتاح التكنولوجي، وكيفية الحصول على ما يفيدنا والابتعاد عن مصادر الضرر. • حثهم على الاستفادة من الفرص الكبيرة التي تتيحها الوسائط الرقمية في دعمهم

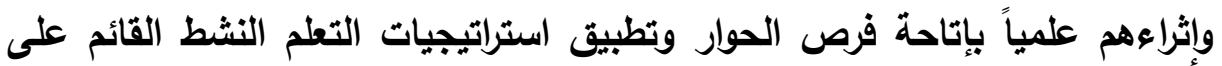
التفكير الناقد والإبداعي. • المساهمة في بناء بيئات تعليمية رقمية تعاونية يتثارك خلالها كل من المعلمين والطلاب في الفصول الدراسية وخارجها عبر الوسائط الرقمية المختلفة (الملاح

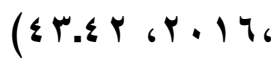


فضلاً عن أن وعي المطلم وحرصه على ترجمة خبراته الإيجابية إلى ممارسة فعلية في المواقف التعليمية تتطلبها المناهج الاراسية والأنثطة والمشكلات المجتمعية لبلورة أبعاد

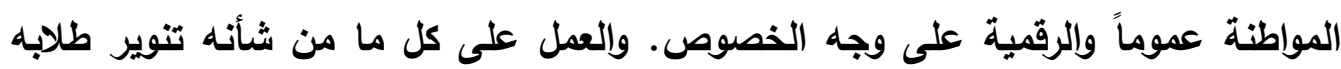
بضرورة الحذر عند التعامل مع منطلبات العصر والتحول الرقمي والاقتباسات، بعدم نقل وإعادة إرسال أفكار مشبوهة مضللة قد تقف خلفها جماعات أو دول معادية، أو تناقل إثناعات ومواضيع فيها مخالفات شرعية أو سياسية أو وطنية أو اجتماعية من شأنها الإضرار بوحدة المجتمع والانتماء الوطني. والعمل على رفع الروح المعنوية لهم للمشاركة الإيجابية لما يحقق المواطنة الرقمية الفاعلة.

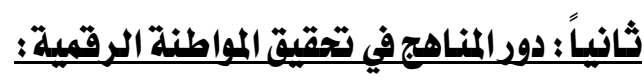
تعد المناهج الدراسية أداة هامة لتحقيق التواصل الفكري والتماسك الاجتماعي في المجتمعات. كما أن لها دورًا هامًا في إعداد الطلاب للحياة والعمل والقيام بدور فعال في العادي

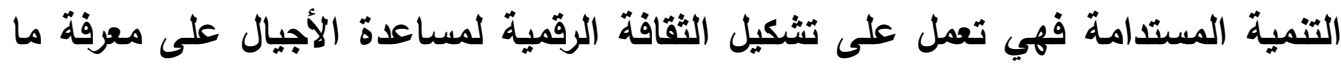

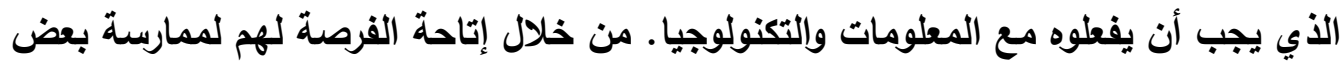

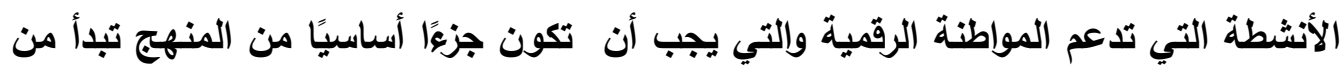
رياض الأطفال ـ بل ويخصص لها منهج مستقل تحت إثراف معلمين متخصصين لغرس قيم التهان المواطنة وتثكيل ثقافة ومهارات المواطنة الرقمية الصالحة.

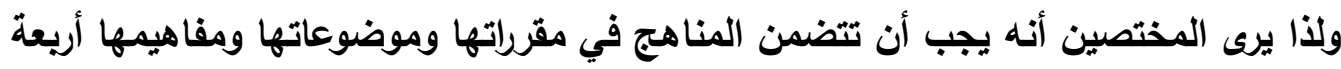
مراحل يمكن بيانها على النحو التالي: 1 - مرحلة الوعى: والذي يتطلب تنمية الوعي المعرفي للطلاب بالتكنولوجيا وكيفية استخامها بالثكل المناسب ، ويالآثار المترتبة على أفعالهم عند استخدامها.

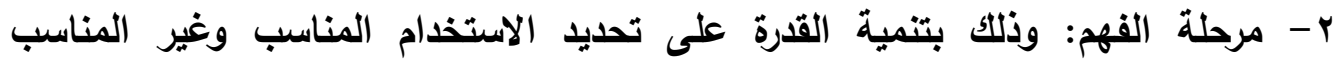
للتكنولوجيا، من حيث القواعد والقوانين الأخلاقية لهذا الاستخدام . ץ- مرحلة الفعل: أي الاستخذام الفعلي للتكنولوجيا بصورة مناسبة بالاعتماد على المعلومات التي تم معرفتها في المرحلتين السابقتين لإتخاذ القرارات المناسبة. 


\section{إسهام المدرسة في تحقيق المواطنة الرقمية لدى طلابها في ظل التحديات المعاصرة.}

ع - مرحلة التقويم: بتقويم الطالب لممارساته الصحيحة والخاطئة وتغيير السلبي منها. وهذه

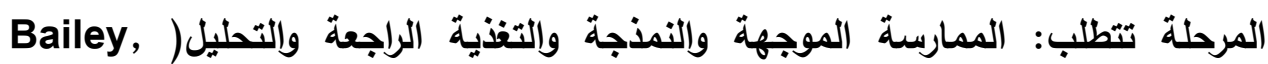

.(Ribble \& 2006, pp. $2-4$

ومجمل القول فإن المناهج يجب أن تعمل على تعزيز المواطنة الرقمية للطلاب بالعمل على تعميم قيم ومهارات المواطنة الرقمية في جميع المناهج الدراسية وتعزيز التربية الوطنية

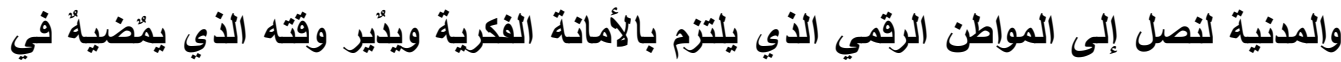

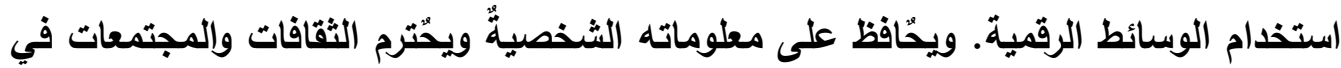

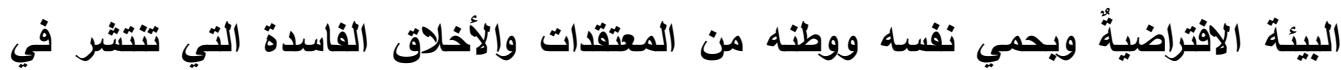
الوسائط الرقمية.(حداد ، ـ 1 ـ ب). وحتى تستطيع المناهج تثكيل ذلك المواطن الرقمي الفعّال فإن ذلك يوجب عليها العمل وفقى المنطلقات التالية : بل

• تعزيز روح المواطنة لدي الطلاب، والتأكيا على الهوية العربية الإسلامية، والحفاظ على القيم المجتمعية في ضوء الانفتاح على الثقافات الأخرى والاتصال بها. • بث المعلومات حول الواجبات الوطنية في جميع الدروس والمقررات ولجميع المراحل عبر الفضاء السيبراني. • توضيح مفهوم المواطنة الرقمية، ومدي الحاجة إليه في هذا العصر الأي يتميز بالإقبال الشديد على استخدام التكنولوجيا في مختلف المجالات. • ربط الطلبة بالنشاطات الوطنية ونشاطات تمثيل الأدوار في جواتب مختلفة من

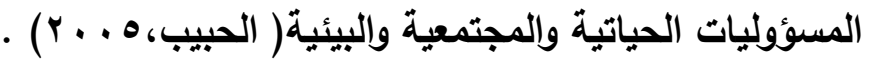
• تهيئة الطالب للاخول إلى مجتمع المعلومات الحديث والتعايش معه، والاستفادة القصوى منها في تنمية المجتمع من الناحية المعرفية، ويناء الاقتصاد الرقمي الوطني. • تمكين الطالب من تحمل مسؤولية الأمن الاكتروني والفكري والحذر من الجرائم المعلوماتية بتنمية ذاته فكريًا وسلوكيًا ومشاركًة ورئيًا ونقدًا وابداعًا. • تعزيز القدرة على الحوار والنقاش الهادف وتقبل آراء الآخرين. • تنمية قدرة الطالب علي إنتاج المعرفة، والتحول من ثقافة النقل إلى ثقافة العقل. 
• تنمية وعي الطلاب بأهمية الحفاظ على هوياتهم الثخصية ويمخاطر إدمان الإتترنت، لما لذلك من آثار خطيرة تتمثل في الانعزال عن المجتمع، والاكتفاء بيناء

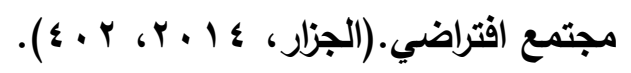

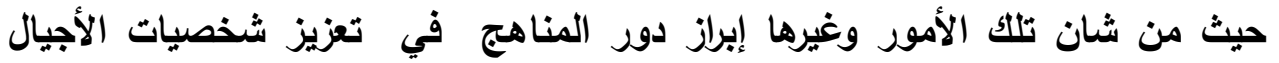
للظفر بالمواطن الرقمي الأي يحب وطنه ويفكر في المصلحة العامة ويستخدم التكنولوجيا بشكل يحميه ويحمي خصوصيته ويحترم القوانين والأعراف وحقوق الآخرين وحرياتهر الإنسانية ويستخدم الإعلام الجديد ووسائطه المتعدة لخدمة قضايا المجتمع والوطن. من أجل ذلك كانت المواطنة وإلتربية الرقمية مسؤولية تقع على عاتق الجميع.( عبد

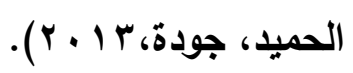

\section{ثالثاً : دور البيئة الملدسية في تيقيق المواطنة الرقيمية:}

مما لاثكك فيه أن البيئة المدرسية الجاذبة تتيح فرص التعليم والتعلّم الممتعة والتي تتعكس إيجاباً على شخصيات الأجيال كما أنها تساهم في تحقيق المواطنة الرقمية بالصورة المرغوية.

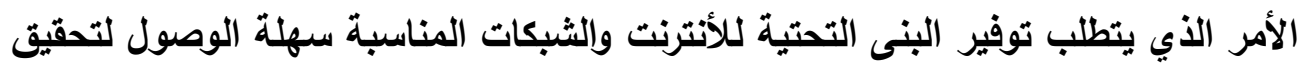
مدي الارتباط بين المواطنة الرقمية ومبدأ تكافؤ الفرص، لما يحقق التوازن في الفروق الفردية

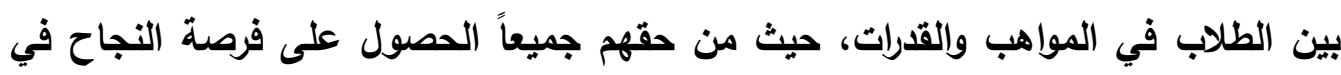

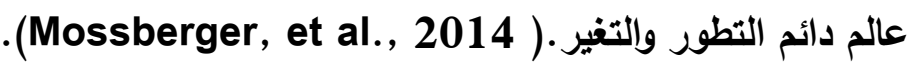
ومن جهة أخرى فإن الثورة الرقمية مثلما أحدثت تغييرًا في طبيعة وملامح الأنثطة الحياتية بصفة عامة، فإنها أدت لظهور مفاهيم وأنماط ومصطلحات جديدة في التربية كالتربية الرقمية ، والتي تسعى إلى تكوين مواطن رقي فعَال، محصن بأطر أخلاقية تحميه من مخاطر الفضاء السيبراني الرقمي، من خلال تربية هدفها تمكين الطلاب نحو التقتية وتنمية مهارات استخدام تقنياتها وتصفح الثبكات الرقمية، بجانب تنمية مهارات التفكير الناقدات لمحتوى تلكك التقتيات والثبكات، في ظل التوجيه المخطط من قبل قائد المدرسة والمطلمين للاستخدام الفعلي للمصادر والتقتيات الرقمية بهاف تنمية المهارات والسلوكيات التي تمكنهم بأن يصبحوا مواطنين رقميين، يتفاعلون مع الآخرين عبر الاتصال المباشر أو أثناء التدريس

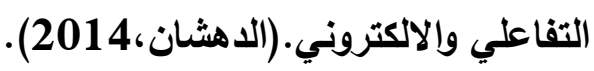


وتستطيع البيئة المدرسية تحقيق تلك التطلعات من خلال العمل وفق المنطلقات

التالية:

ا. أن تتبنى المدرسة التحول الرقمي بكل بيئاتها وأجهزتها وعناصرها ومناهجها، كما تتحول مواضيع الدراسة إلى مسائل يستتنونها عبر تقتيات رقمية تنمي فيهم روح الاكتثاف والإبداع ، ومواكبة العصر ليعملوا بأدوات من نتاج الثورة التكنولوجية المعاصرة. r. توفير الإمكانات والتتقيات في البيئة المدرسية بتصميم موقع إلكتروني للمدرسة يضم جميع فعاليات العملية التعليمية، ويعرف المجتمع بجهودها، ويسمح للطلاب بالتعبير عن آرائهم حولها ـ كما يمكن للطلاب والمعلمين من خلاله التواصل مع بعضهم البعض، ومع الإدارة، وأولياء الأمور لكل ما يخدم عمليات التعليم والتعلّم. r. إتاحة فرص توظيف استراتيجيات التعلم الحديثة لتعزيز مهارات الحوار والتواصل واحترام آراء وأفكار الآخرين ومهارات الإصغاء النشط، وحثهم على الاثتراك في الملتقيات، والمنتديات، والمدونات وجلسات النقاش التي تتيحها شبكات التواصل الاجتماعي لبحث القضايا التي تهمهم في حاضرهم ومستقبلهم.(عروية ، 2010).

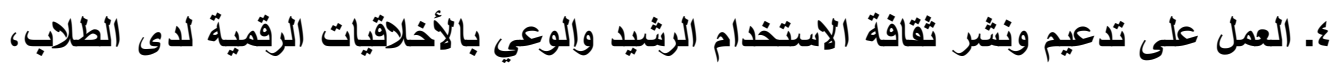
وتدريبهم على ممارسة جميع جوانب المواطنة الرقمية من خلال كافة الفعاليات والبرامج التريوية والأنثطة المدرسية المناسبة لإعدادهم وتربيتهم على المواطنة الرقمية ليتمكنوا من الحياة بأمان في العصر الرقمي(الدهشان والفيطه الفيهي، 2015). ويتفق الباحث مع ما ذهب إليه البعض بأن مجتمعنا السعودي وعالمنا العربي أصبح في المئي حاجة ماسة إلى مبادرات ويرامج تريوية مدرسية ومجتمعية في التربية والمواطنة الرقمية والاستدامة فيها لحماية شبابنا وتعزيز سلامتهم من الاستخدامات السلبية المتزايدة للتكنولوجيا الحديثة في العصر الرقمي، وخاصة التوعية بالسلامة والأمن الإكتروني عند الأبند

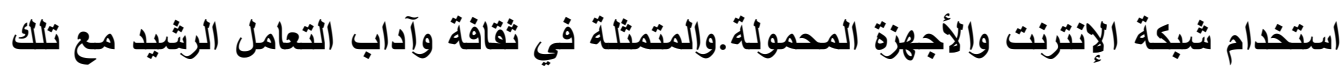
التكنولوجيا الرقمية.( سلامة، 2013)

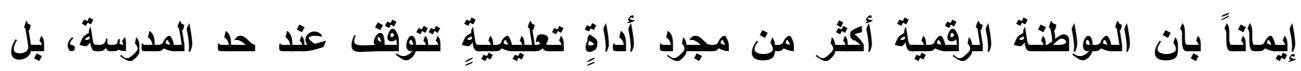
تتخطى ذلك الى إعداد الطالب ليكون مواطن رقمي ينخرط في مجتمعه ولتصبح سلوكاً يلازم 
الطالب في أي مكان وزمان، فضلاً عن الإسهام في إعداد أفراد قادرين على المشاركة

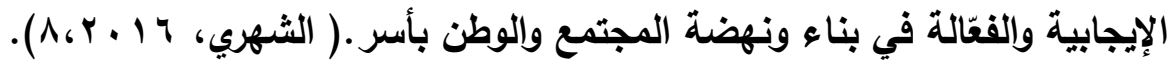
رابعاً: دور القائد التربوي في تخقيق المواطنة الرقمية: للقائد التربوي دور كبير في تسيير عملية التربية والتعليم في مدرسته، وتحقيق الأهداف التريوية من خلال ما يمارسه من أدوار فهو يعمل كقائد قدوة ومرشد ومشرف وموجه. كما أنه يقيم جسور التكامل التريوي مع المؤسسات التربوية ويقيم الثركات المجتمعية للمساهمة في لتمني تنشئة الأجيال تنشئة متكاملة ويناء شخصياتهم وصقلها بما يعود عليهم وعلى مجتمعاتهم

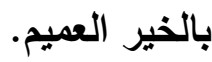
ولهذا فللقائد التريوي دورًا كبيرًا في تحقيق المواطنة الرقمية في ضوء التحديات المعاصرة بما يقوم به من مهام داخل الميدان وخارجه، وإسهامه في تربية الفرد وإعداده للحياة . وحتى يسهم قائد المدرسة في تحقيق المواطنة الرقمية وقيمها داخل الميدان التعليمي فإنه يقع عليه قيادة التغيير الهادف لتحقيق أقصى حد ممكن من أهداف التعلّم بالتخطيط وإلتظيم

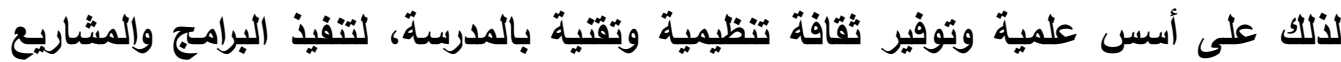
والنشاطات والإشراف والتوجيه والتقييم، حيث يتولى مدير المدرسة توجيه العاملين معه من

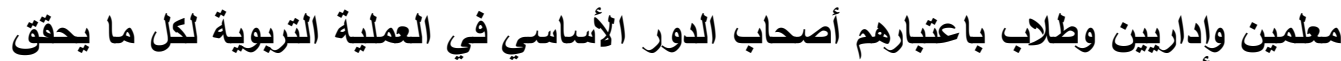
المواطنة الرقمية (Heaser, , 2012 ). كما يتعين على القائد التريوي أن يوجه العاملين معه إلى المواطنة الرقمية، ومعرفة الأهداف المنشودة من تحقيقها، وكذا توجيه المتعلمين بما يتفق وخصائص نموهم العقلي والنفسي والانفعالي والجسمي ومنطلبات المجتمع التريوية، وتتمية القيم الأخلاقية والحميدة والمثل العليا لاى الطلاب نحو التقتية الرقمية والاستخدام الأمثل لها. مع العمل علي توفير الموارد التقتية والتعليمية اللازمة والتي تمكن المعلمين والمتعلمين من الوصول لأفضل فهم للتكنولوجيا الرقمية وكيفية الاستفادة منها في عمليتي التعلّم والتعليم، وزرع وتنمية قيم المواطنة الرقمية لاى الطلاب. هذا بالإضافة إلى إسناده تدريس المواطنة الرقمية والتتوعية بها لمن هو جدير من المعلمين الأكفاء بتحديد من سيتولى تدريس المواطنة الرقمية سواء(المعلمون أو المتخصصون في التكنولوجيا أو المتخصصون في المناهج بالمدرسة). مع تشجيعه لهم على 


\section{إسهام المدرسة في تحقيق المواطنة الرقمية لدى طلابها في ظل التحديات المعاصرة.}

تطوير ومراجعة المنهج ـ وحثه لهم على توظيف التعليم الاككتروني وتقتيات الاتصال الرقمي مثل شبكات التواصل الاجتماعي في استراتيجيات التدريس ودعم الابتكار والإبداع في التدريس، وكذلك الاستفادة منها في دعم أنشطة الطلاب داخل و خارج الصف ، ومشاركة الأفكار مع الآخرين. عبر الفضاء السيبراني وكل ما من شأنه مساعدتهم علي التحسين المستمر لتعلّم العصر الرقمي وتطبيق المواطنة الرقمية وتزويدهم بالكفايات والمهارات اللازمة لضمان حسن الاستخدام الواعي للتكنولوجيا بفاعلية. كما يمتد دور قائد المدرسة إلى تلمس حاجات طلابه والمجتمع المحيط بتعزيز التفاعلات الاجتماعية المسؤولة ذات الصلة بالتحول الرقمي واستخدام تكنولوجيا معلومات، والعمل مع فريق عمله بالمدرسة على نشر الوعي بالمواطنة الرقمية وتنمية قيمها وطرق تحقيقها في ضوء التحديات المعاصرة من خلال الفعاليات والبرامج والأنشطة المدرسية والتدوات، والدورات والمؤتمرات وإجراء البحوث العلمية والإجرائية والمسابقات الثقافية التي تدور حول كافة القضايا المتعلقة بحقوق وواجبات المواطن في العصر الرقمي ومجالات ومحاور المواطنة

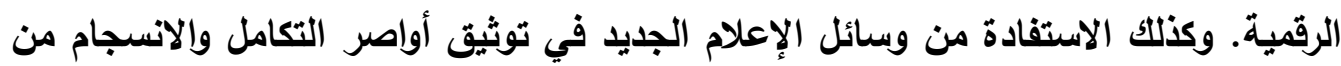
خلال تخطيط تشاركي. ووعي مجتمعي مساند. لتنشئة المواطن الرقمي الواعي الأي يدرك لرك أبعاد الثقافة الرقمية ويستطيع توظيفها باحترافية في حياته اليومية ورفعة وطنه.

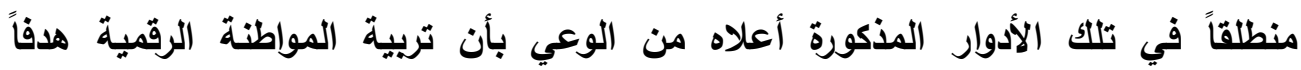
استراتيجياً للنظم التريوية لمساعدة الأجيال على تطوير قراتهم وطاقاتهم ليكونوا مواطنين صالحين في المجتمع، منتجين ومساهمين ومسؤولين ومهتمين بشؤون مجتمعهم وقضاياه وهمومه وأولوياته، ومحافظين على نسيجه وهويته. (درهم،2006).

النتتائج والتوصيات أولاً : النتتائج : من خلال ما تم استعراضه في فصول الاراسة يمكن بيان أهم النتائج التي تم الوصول إليها على النحو التالي : ا. للمطم دور في غرس قيم المواطنة الرقمية وتنميتها لاى الأجيال من خلال توظيف التقتية في العملية التعليمية وتفعيل استراتيجيات التعلم النشط القائم على التفكير الناقد والابتكاري. 


\section{إسهام المدرسة في تحقيق المواطنة الرقمية لدى طلابها في ظل التحديات المعاصرة.}

r. تساهم المناهج في تحقيق المواطنة الرقمية ببث قيمها ومفاهيمها وأهميتها ومجالاتها وتحدياتها المعاصرة عبر المراحل التعليمية المختلفة والمقررات الدراسية المتنوعة . r. امتلاك البيئة المدرسية لمقومات تقنية عالية وتوظيفيها للأنشطة الصفية واللاصفية يساهم في إعداد المواطن الرقمي المحقق للمواطنة الرقمية والواعي بلوره الفاعل فيها ـ مأدة

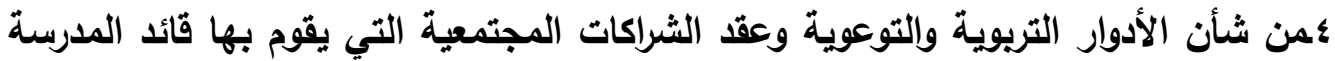
تحقيق المواطنة الرقمية والمسؤولية الإكترونية التي تعود على المدرسة والمجتمع

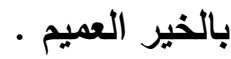
ه. يساهم تكامل الأدوار بين عناصر العملية التعليمية بالمدرسة في قيادة مسار التحول الرقمي وتثكيل شخصيه المواطن الرقمي الواعي بالاستخدام الرشيد للتقتيات الرقمية ،

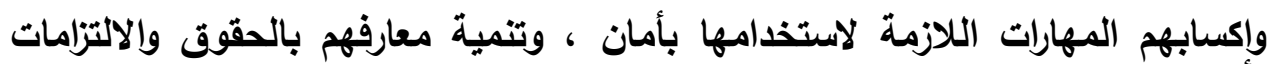
والواجبات الرقمية.

צ. لعناصر العملية التعليمية بالمدرسة دور في تحقيق المواطنة الرقمية لدى الطلاب في المراحل العمرية المختلفة من خلال تثكيل العصانة الفكرية والذاتية وإدراك حجم التحديات المعاصرة التي أفرزتها التقتيات الرقمية الدديثة واستخداماتها وتأثيراتها عليهم

$$
\text { وعلى الآخرين. }
$$

V ـ لعناصر العملية التعليمية بالمدرسة دور في تحقيق المواطنة الرقمية لدى الطلاب بتعزيزها الهوية الوطنية والعربية الإسلامية، والحفاظ على القيم المجتمعية في ظل الانفتاح على لابل الثقافات الأخرى والاتصال بها. ^ ـ للمعلم والقائد التريوي والمناهج والبيئة المدرسية دور في تحقيق المواطنة الرقمية لاى

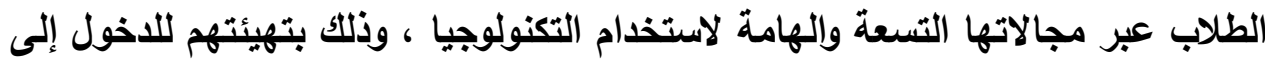
مجتمع المعلومات الحديث والاستخدام الأمثل، والاستفادة القصوى منها في تنمية المجتمع من الناحية المعرفية، ويناء الاقتصاد الوطني الرقمي. 9 ـ للمعلم والقائد التربوي والمناهج والبيئة المدرسية دور في تحقيق المواطنة الرقمية لاى الى الطلاب بتنمية الوعي لايهم بتحمل مسئولية الأمن الالكتروني والحذر من الجرائم 
ا التوصيسات :

في ضوء النتائج السابقة وما تم تناوله في فصول الدراسة توصي الدراسة بما يلي :

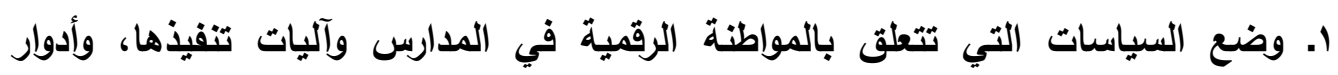
ومسئوليات عناصر العملية التطليمية في عمليات التنفيذ.

r. تخصيص منهج مستقل للمواطنة الرقمية في جميع المراحل الاراسية يقوم على اختيار

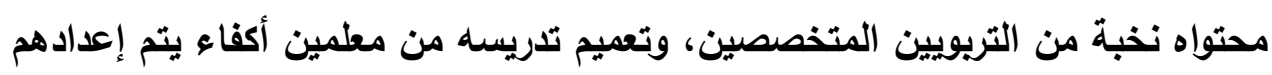

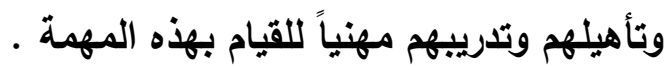
r ـ استضافة المختصين البارزين في التقتية وغيرهم من المتخصصين الأمن السيبراني لتوعية الطلاب حول أهمية التحول الرقمي وعلاقته بالمواطنة الرقمية ومجالاتها

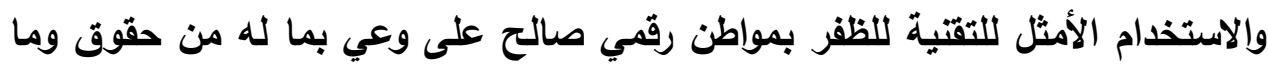

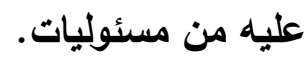

؛ . إجراء دراسة ميدانية عن واقع اسهام المراحل التعليمية الدراسية في تحقيق المواطنة

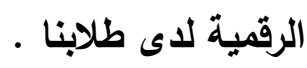

ه. إجراء دراسة عن دور الجامعات في المملكة العربية السعودية في تحقيق المواطنة الرقمية. 


\section{المراجع}

• الجزار، هالة حسن سعد (ع ا بـ): دور المؤسسة التربوية في غرس قيم المواطنة الرقمية،

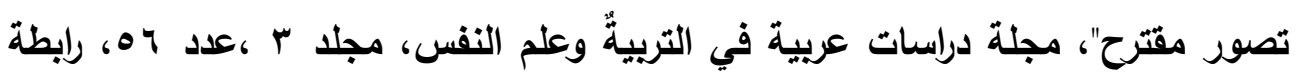

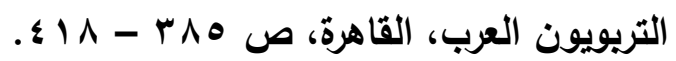

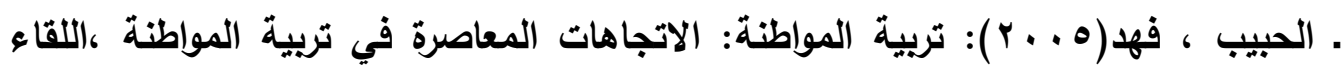
الثالث عشر لقادة العمل التربوي ، الباحة.

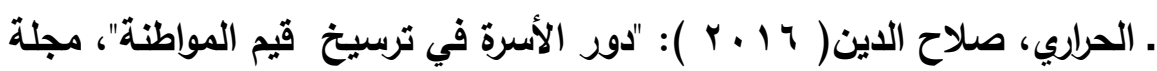

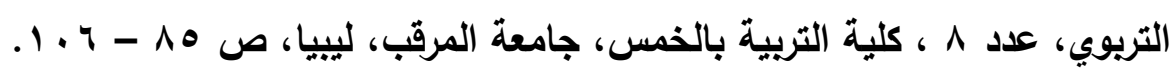

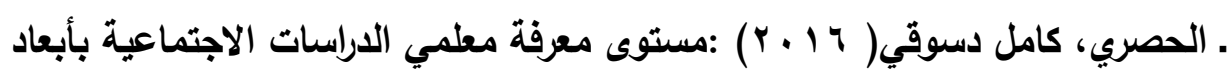

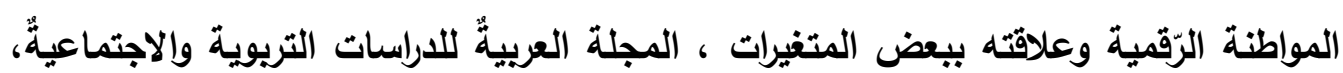

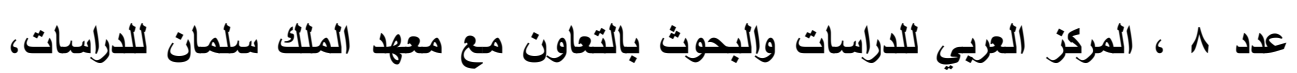

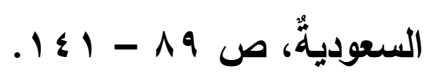

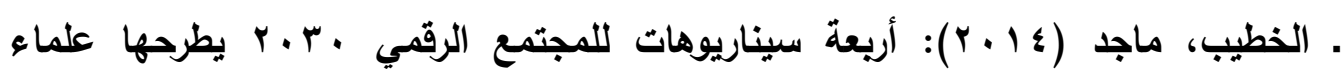
سويسريون . http://elaph.com/Web/News/2014/10/952244.html

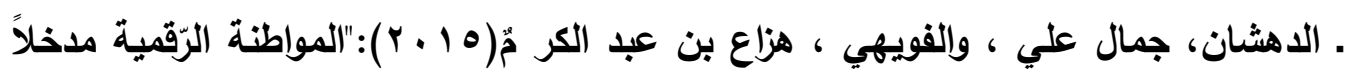

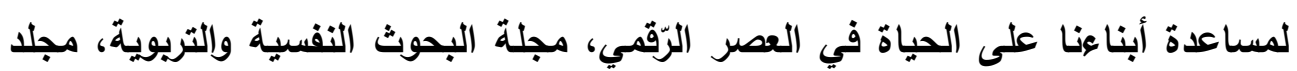

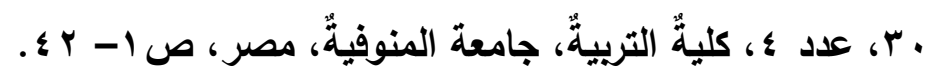

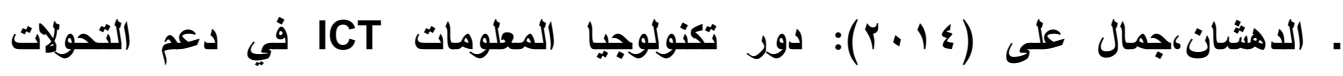
الديمقرطية الرقمية (Digital Democracy) نموذجاً - ورقة عمل مقدمة إلى المؤتمر

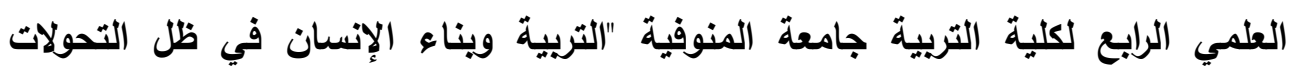

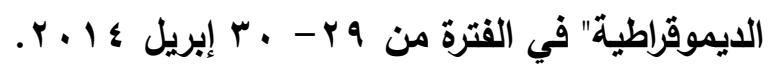

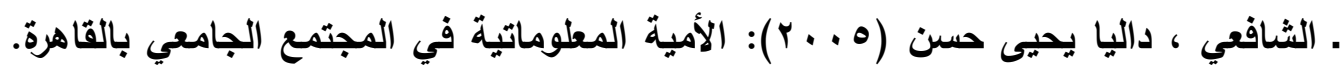

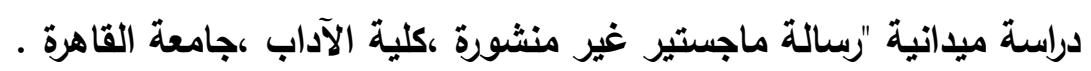




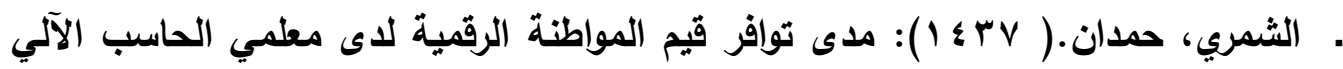

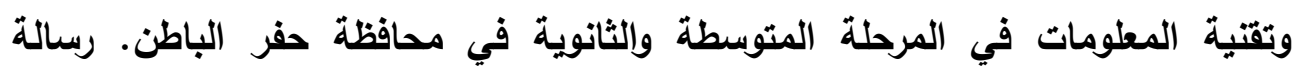

ماجستير

غير منشورة. جامعة الملك سعود. السعودية.

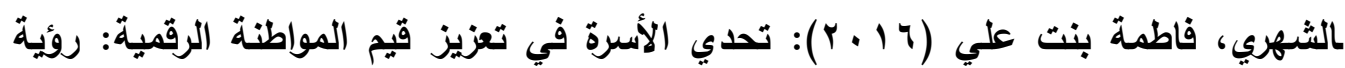

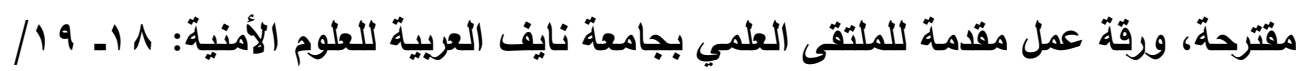

$$
\text { . } 17 / 1 \text {. }
$$

ـ العقيل ، عصمت ابراهيم (؟ ا ـ ب): المواطنة في الفكر التربوي الاسدلامي ، دار اليازوري، - الاردن

• المسلماني ، لمياء إبراهيم (ع ا • r): التعليم والمواطنة الرقمية : روئة مقترحة. عالم

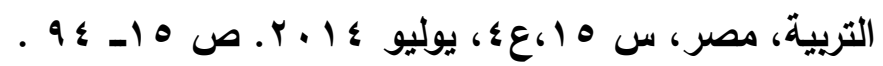

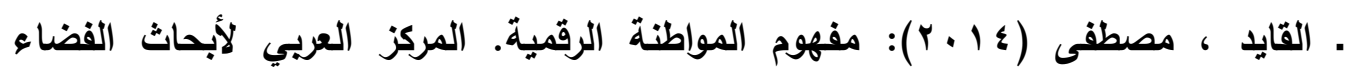
http://www.new-educ.com/definition-of- الإكتروني، متاح على الرابط:

\section{digital-citizenship}

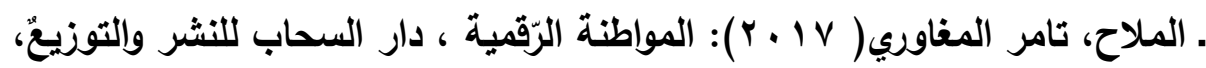
القاهرة. ـ الهيئة العامة للإحصاء (1 1 ـ ץ): الكتاب الاحصائي السنوي لعام 1 ـ ـ بم،المملكة العربية

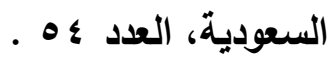
· جمال الدين ، ابن منظور (؛99 1): لسان العرب، المجلد الثالث عشر ، دار صابر،

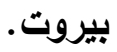

• درويش، محمد احمد(9 . . r): العولمة وإلمواطنة ،عالم الكتب ، القاهرة ،مصر .

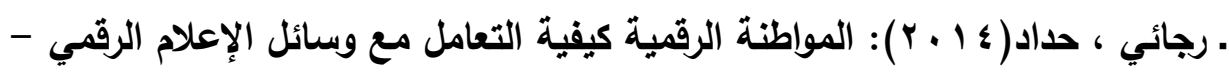
والتكنولوجيا والتقتيات الحديثة بحيث تصبح عوامل بناء وتطور وتعلم للجيل الجديد .

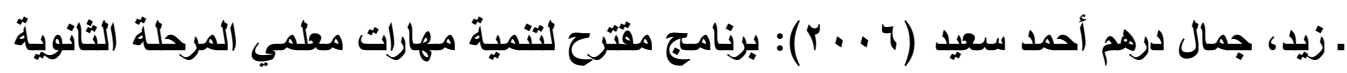

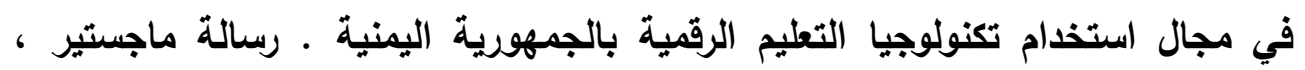
أكاديمية السادات للعلوم الإدارية. 


\section{إسهام المدرسة في تحقيق المواطنة الرقمية لدى طلابها في ظل التحديات المعاصرة.}

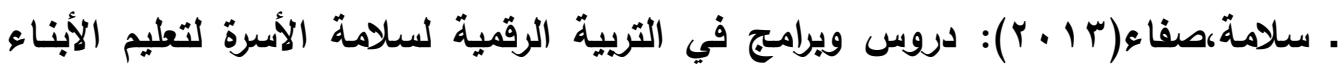

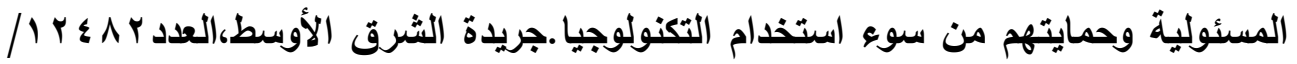

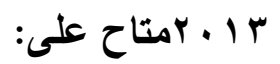

classic. aawsat.com/details. asp? section=54\&article $=715127 \&$ issue no 482\#.U-Wz7PQW2So

ـ شرف، صبحي شعبان علي، الدمرداش، محمد السيد أحمد (؟ ا ـr): معايير التربية على المواطنة الرقمية، وتطبيقاتها في المناهج الدراسية ـ المؤتمر السنوي السادي "أنماط" التعليم ومعايير الرقابة على الجودة فيها"- المنظمة العربية لضمان الجودة في التعليم -

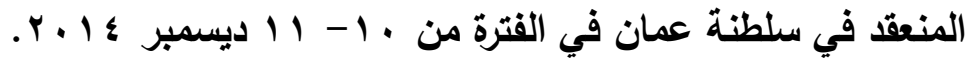

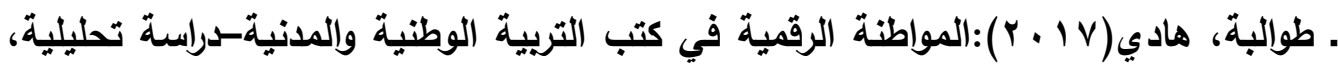

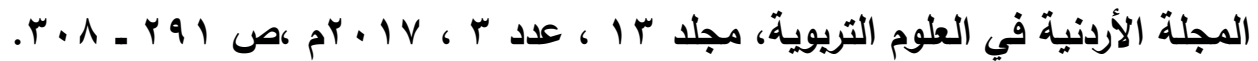

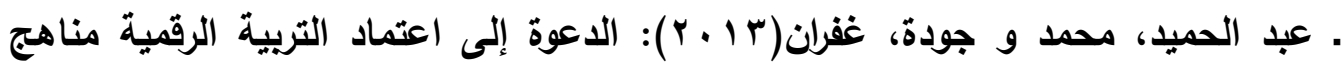

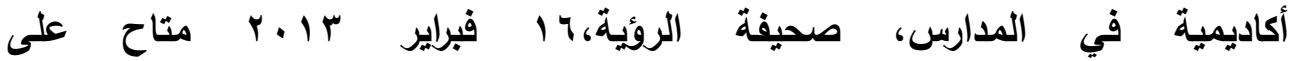
alroeya.ae/2013/02/16/29385.

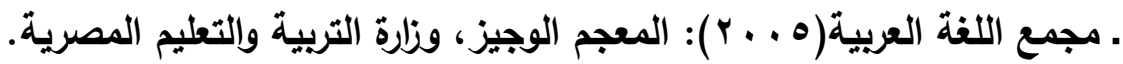

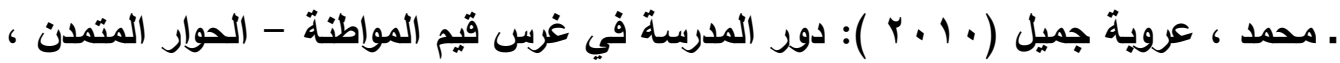
2 2909 العدد: (المد

.http://www.ahewar.org/debat/show.art.asp?aid=202493

- Heaser, Cherie. (2012). "How do you become a Responsible Digital Citizen?" Library Media Connection. May/ June.

- Hoover, Michelle \& Kyle, Bobbi (2014). Developing Digital Citizenship Through Project-based Learning, University of Britsh Columbia , ETEC Intel education (2014). Digital Citizenship ,https://nata3alam.intel. com/ar/event/1205 .

- Hollandsworth, Randy; Dowdy, Lena; Donovan, Judy (2011): Digital Citizenship in K-12: It Takes Village, Tech Trends: Linking Research and Practice to Improve Learning, Vol. 55, No. 4, Association Management Software Powered by Your Membership, Bloomington, P37-47. 


$$
\text { إسهام المدرسة في تحقيق المواطنة الرقمية لدى طلابها في ظل التحديات المعاصرة. }
$$

- Dotterer, George; Hedges, Andrew; Parker, Harrison (2016): Fostering Digital in the Classroom, Education Digest Journal, Vol. 82, No. 3, Vilnius, Lithuania .

- Bolkan,. (2014): Resources to Help You Teach Digital Citizenship, T H E Journal, Vol. 41 No. 12, P21-23.

- Mossberger, Karen , Tolbert, Caroline J , and Anderson, Christopher (2014). Digital Citizenship : Broadband, Mobile Use, and Activities Online , International Political Science Association Conference, Montreal , July, 2014.

- Ribble,. (2011). Nine Themes of Digital Citizenship. Available at: digitalcitizenship.net / Nine Elements.html. Retrieved on 1 August 2014.

- Ribble,; Bailey, G. (2006). Digital Citizenship at all grades levels, International Society for Technology and Education. Information Literacy: Available at: www.iste.org. Retrieved on 1 August 2014.

- Young, Donna (2014). A21st-century model for teaching digital citizenship , educational horizons, February/march 2014. 